\title{
Cholera toxin adjuvant promotes a balanced Th1/Th2/Th17 response independently of IL-12 and IL-17 by acting on Gs $\alpha$ in CD11b ${ }^{+}$DCs
}

\author{
J Mattsson ${ }^{1}$, K Schön ${ }^{1}$, L Ekman ${ }^{1}$, L Fahlén-Yrlid ${ }^{1}$, U Yrlid ${ }^{1}$ and NY Lycke ${ }^{1}$
}

Despite an extensive literature on the mechanism of action of cholera toxin (CT), we still lack critical information about how the toxin acts as an adjuvant and, especially, which dendritic cells (DCs) are the target cells. Although a Thelper type 2 (Th2)-skewing effect of CT is most commonly reported, effective priming of Th17 cells as well as suppression of Th1 responses are well documented. However, the ability of CT to block interferon regulatory factor 8 (IRF8) function and interleukin (IL)-12 production in DCs, which blocks CD8 $\alpha$ DC and Th1 cell development, is inconsistent with priming of Th1 and CD8 T cells in many other reports. This prompted us to investigate the adjuvant effect of CT in wild-type, IL-12p40 - / - , Batf3 - I - , and IL-17A - / - mice and in mice that selectively lack the Gs $\alpha$ target protein for CT adenosine diphosphate (ADP)-ribosylation in DCs. We found that CT promoted Th1 priming independently of IL-12, and whereas Th2 and also Th17 responses were augmented, the gut IgA responses did not require IL-17A. Adjuvanticity was intact in Batf3 - / - mice, lacking CD8 $\alpha^{+}$DCs, but completely lost in mice with Gs $\alpha$-deficient CD11c cells. Thus, our data demonstrate that the adjuvant effect requires Gs $\alpha$ expression in CD11b ${ }^{+} \mathrm{DCs}$, and that priming of mucosal IgA and CD4 T cells appears unbiased and is independent of IL-12 and IL-17A.

\section{INTRODUCTION}

Although mucosal vaccination is considered an attractive route for vaccine delivery, the lack of safe and effective adjuvants for clinical use has greatly delayed the development of such vaccines. ${ }^{1}$ The closely related adenosine diphosphate (ADP)ribosylating bacterial enterotoxins, cholera toxin (CT) and Escherichia coli heat-labile toxin, are unfortunately too toxic to be approved for human vaccination, a consequence of their upregulating effect on intracellular cyclic adenosine monophosphate (cAMP) levels. Notwithstanding this, there is a general consensus that they are among the strongest adjuvants known today, not only for mucosal, but also for parenteral vaccination. ${ }^{2-5}$ Despite an extensive literature on the mechanism of action of CT and Escherichia coli heat-labile toxin, we still lack critical information about how these toxins augment cellmediated as well as humoral immune responses. ${ }^{3,6-8}$ For example, although several studies have identified dendritic cells (DCs) as critical target cells for the adjuvant function, the data are conflicting and there is not a distinct subset of DCs that is known to convey the adjuvant effect. ${ }^{9-17}$ Even more confusing is the fact CT has been considered a strong $\mathrm{T}$ helper type 2 (Th2)-skewing adjuvant, although many investigators, including our own work, have attested to an effective interferon- $\gamma$ (IFN- $\gamma$ )- and Th1-promoting function of CT. ${ }^{17-22}$ In particular, elegant studies by la Sala et al..$^{23}$ demonstrated that CT, through upregulation of intracellular cAMP in DCs, inhibited the transcription factor IRF8 (interferon regulatory factor 8) and thereby blocked IL-12 production as well as the differentiation of plasmacytoid DCs and CD $8 \alpha^{+}$conventional DCs (cDCs). Furthermore, the expression of the interleukin (IL)-12 receptor was reported impaired after exposure to CT. ${ }^{24}$ Thus, the consequence of CT treatment was a defective Th1protective immune response and lethal susceptibility to Toxoplasma gondii infection. ${ }^{23}$ However, in contrast, upregulation of intracellular cAMP in CD4 $\mathrm{T}$ cells has been shown to augment Th1 differentiation, and mice lacking Gs $\alpha$ in CD4 $\mathrm{T}$ cells, the substrate for the CTA1 enzyme, displayed reduced frequencies of Th1 cells. ${ }^{25,26}$ These seemingly conflicting

\footnotetext{
${ }^{1}$ Department of Microbiology and Immunology, Institute of Biomedicine, University of Gothenburg, Gothenburg, Sweden. Correspondence: NY Lycke (nils.lycke@gu.se) Received 22 February 2014; accepted 6 October 2014; published online 26 November 2014. doi:10.1038/mi.2014.111
} 
observations provide alternative explanations to a Th1promoting or -suppressing effect of CT in vivo. In addition, several studies have documented enhanced Th17 responses in response to the CT adjuvant, indicating that CT does not only promote Th1 or Th2 differentiation, but that differentiation to several different CD4 T-cell subsets, including Th17 and type 1 regulatory $\mathrm{T}$ cells, can be possible outcomes. ${ }^{22,27-29}$ Accordingly, cAMP increases in DCs were shown to preferentially lead to Th17 differentiation in vitro, a mechanism that appeared to also influence the ability of CT to act as an IgA-promoting adjuvant in vivo as assessed in IL-17A-deficient mice. ${ }^{29}$ However, Hirota et al. ${ }^{30}$ identified that it was the Th17 subset, a

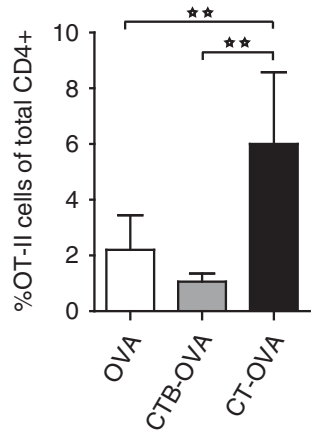

b

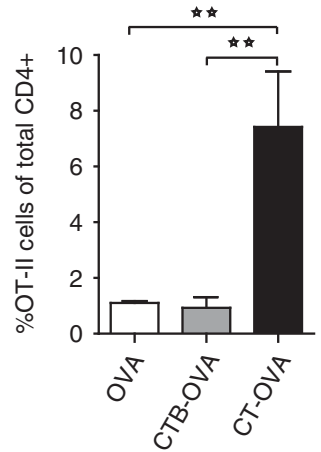

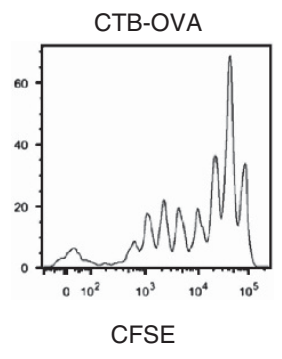
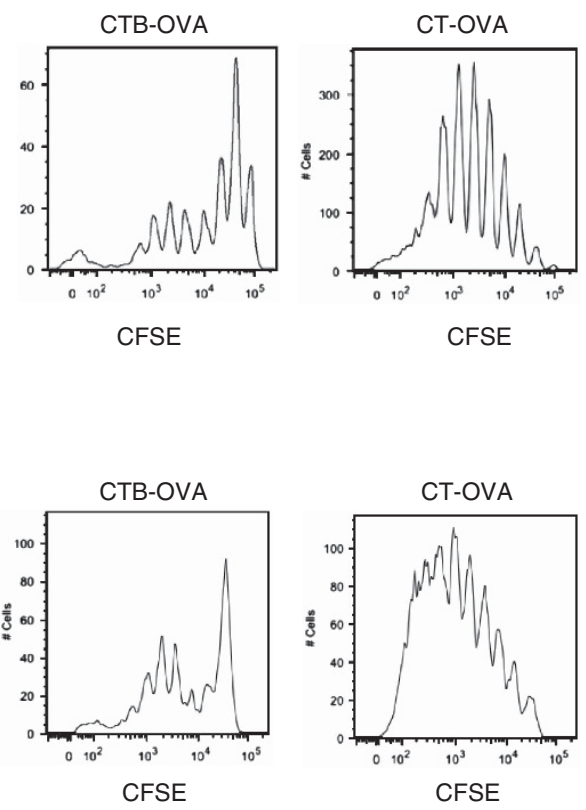

C
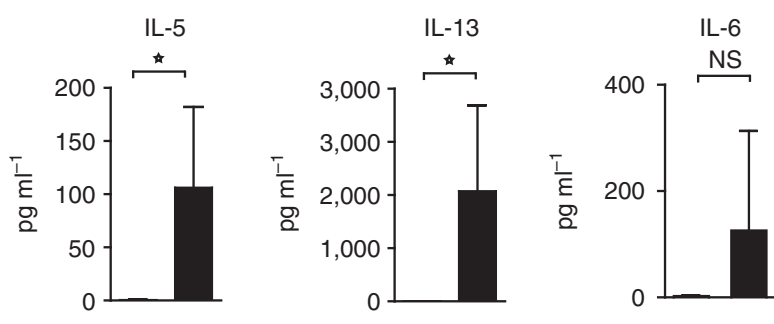

IL-10

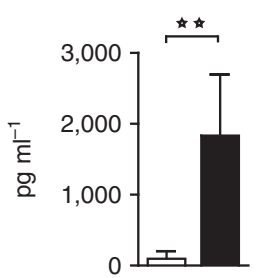

IL-17A

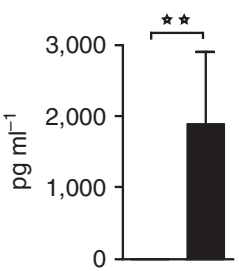

$\square$ OVA

CT-OVA

Figure 1 Cholera toxin (CT) induces a balanced Th1/Th2/Th17 response following intravenous (i.v.) or intranasal (i.n.) immunizations. Mice (CD45.2 ${ }^{+}$) were given carboxyfluorescein succinimidyl ester (CFSE)-labeled CD45.1 $1^{+}$OT-II transgenic T cells by adoptive transfer and were subsequently immunized i.n. or i.v. with ovalbumin (OVA), CTB-OVA, or CT-OVA on the next day. On day 9, the mice were killed and cells from the (a) mediastinal lymph node ( $\mathrm{mLN}$ ) after i.n. immunization or (b) spleen after i.v. immunization were isolated. $(\mathbf{a}, \mathbf{b})$ The CFSE profile and the frequency of OT-II cells from the (a) $\mathrm{mLN}$ or the (b) spleen of i.n. or i.v. immunized mice, respectively, was determined by flow cytometry. (c,d) Lymphocytes from the $\mathrm{mLN}$ or the spleen from CT-OVA or OVA i.n. (c) or i.v. (d) immunized mice were cultured in triplicates with recall antigen OVA for $96 \mathrm{~h}$, after which supernatants were collected and assessed for cytokine production. (e) CD45.1 ${ }^{+}$OT-II T cells were sorted from the spleen of CT-OVA or phosphate-buffered saline (PBS) i.v. immunized mice and the mRNA expression of Tbx21, GATA-3, CCR4, and Maf was determined by real-time PCR (RT-PCR). Statistical significance was calculated using (a,b) analysis of variance (ANOVA) with Dunnett's posttest or (c-e) Student's $t$-test. ${ }^{\star} P<0.05$, ${ }^{* \star} P<0.01$, NS, not significant. Data are representative of at least two identical experiments with five mice per group, and are shown as mean $\pm \mathrm{s}$.d. CTB, cholera toxin B subunit; IFN- $\gamma$, interferon- $\gamma$; IL, interleukin; Th, T helper. 

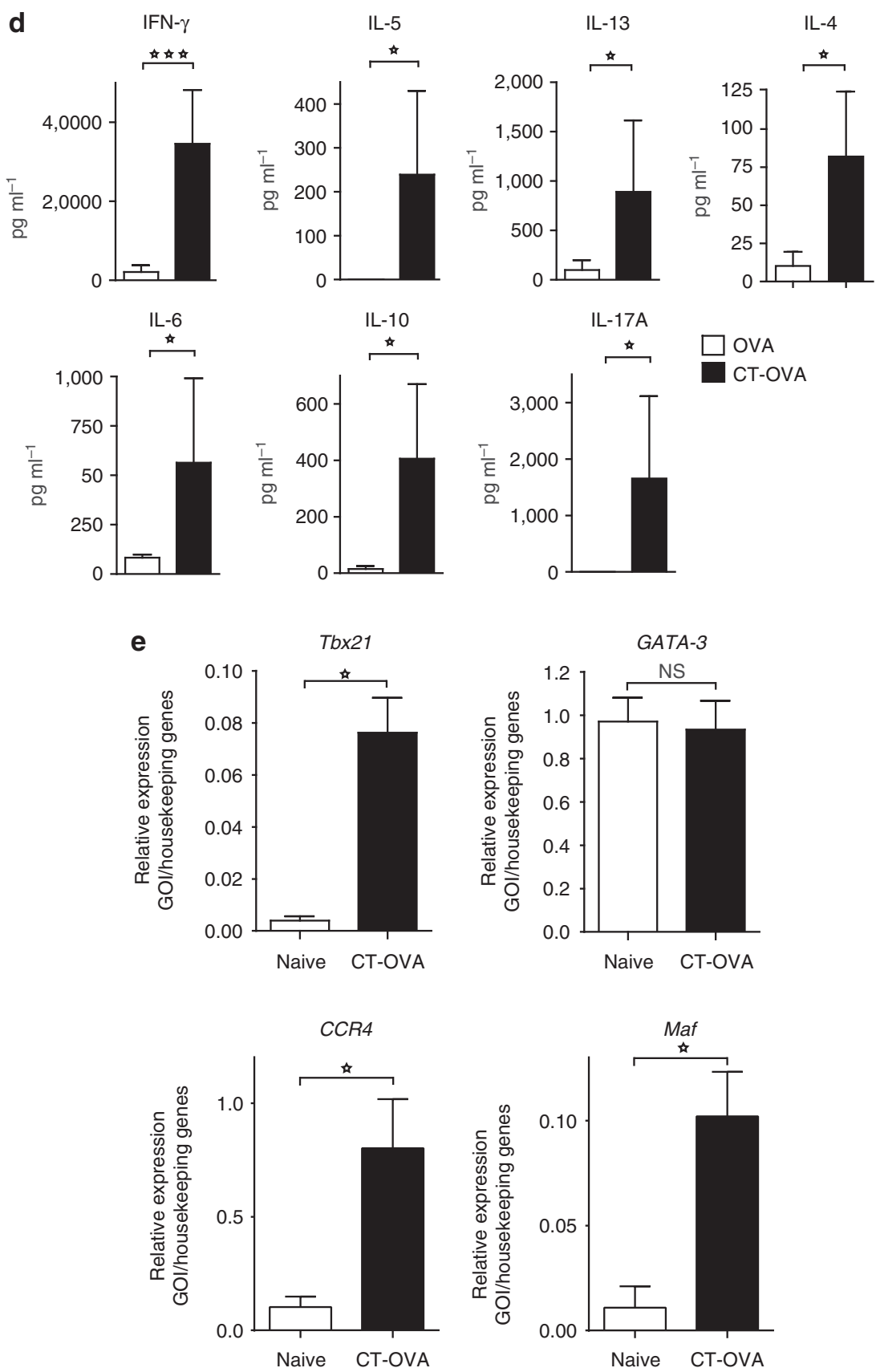

Figure 1 Continued.

rather than IL-17A, that was crucial for follicular helper T cell development in Peyer's patches (PPs) and, hence, indirectly influenced the mucosal IgA-inducing ability of CT.

Although most studies have linked the adjuvant effect of CT to cAMP rather than to its ability to bind to the GM1 ganglioside receptor, no previous study has conclusively demonstrated that cAMP is involved in the adjuvant mechanism in vivo. We have shown that ADP-ribosylation is critical because the CTA1-DD adjuvant, which exerts comparable adjuvant effects to those of CT, is critically dependent on the enzymatic activity. ${ }^{31}$ Whereas the adjuvant mechanism of CT required the expression of GM1 ganglioside receptors on DCs, we do not know whether ADP-ribosylation of Gs $\alpha$ is essential. ${ }^{32}$ This study was undertaken to gain further insights into the mechanisms responsible for the adjuvant effect of CT and, in particular, the role of Gs $\alpha$ in DCs and what effect this has on CD4 T-cell priming. The impact of CT, especially on DC subsets, was studied following intranasal (i.n.) or intravenous (i.v.) immunizations in wild-type (WT), Batf3-/-, IL-17A - / - , and IL-12p40-/ - mice, and in mice that we developed with a selective defect in Gs $\alpha$ expression in CD11c ${ }^{+}$cells. 


\section{RESULTS \\ The CT adjuvant effectively primes Th1 as well as Th2 and Th17 CD4 T cells following either mucosal or parenteral immunizations}

We and other research groups have repeatedly observed exceptionally potent Th1-priming ability when using CT adjuvant, despite its reputed ability to block IL-12 production. ${ }^{3,13,18,20-22,33}$ To investigate these seemingly conflicting results, we undertook a series of experiments to compare CD4 T-cell responses following either i.n. or i.v. immunizations using CT. To this end, we first adoptively transferred carboxyfluorescein succinimidyl ester (CFSE)-labeled ovalbumin (OVA)-specific OT-II cells into WT recipients and subsequently immunized the mice with CT conjugated to OVA i.n. or. i.v. We found that CT-OVA conjugate was highly effective in stimulating proliferation of OT-II cells, whereas OVA alone gave poor priming of the CD4 T cells, irrespective of whether immunizations were given i.n. or i.v. (Figure1a,b). Cytokine production to recall antigen showed that lymphocytes from the spleen or the draining mediastinal lymph node from CT-OVAimmunized mice produced IFN- $\gamma$, IL-4, IL-5, IL-13, IL-10, IL-6, as well as IL-17A, cytokines suggesting differentiation to Th1, Th2, as well as Th17 cells (Figure 1c,d). Moreover, mRNA expression of transcription factors from sorted OT-II CD4 $\mathrm{T}$ cells in these mice revealed a potent induction of the Th1 transcription factor T-bet, and, as expected, expression levels of CCR4, Maf, and GATA3 mRNA also revealed induction of Th2 cells (Figure 1e,f).

\section{CT induces Th1 responses independently of IL-12}

Given that CT has been shown to inhibit IL-12 production by antigen-presenting cells, ${ }^{23,24}$ we asked whether the observed IFN- $\gamma$ response in OT-II cells could have been generated independently of IL-12. To this end we again adoptively transferred naive OT-II cells into IL-12p40 - / - or WT mice followed by i.v. immunizations with CT-OVA (Supplementary Figure S1 online). We found that the CT adjuvant was able to enhance CD4 T-cell responses and promote IFN- $\gamma$ production even in the complete absence of IL-12 (Figure 2a-e) Furthermore, we observed enhanced and comparable expression of the transcription factors T-bet and GATA-3 in OT-II cells from WT and IL-12p40-/ - mice, supporting the idea of a strong IL-12-independent Th1 differentiation as well as Th2 differentiation promoted by CT (Figure 2f). In contrast, CT upregulated the expression of Rorc in WT mice, but not in IL-12p40 - / - mice, probably because of the lack of IL-23 in these mice (Figure 2f). ${ }^{34,35}$ A Th1-promoting effect was also supported by the similar levels of specific serum IgG2c antibody responses in WT and IL-12p40-/ - mice, resulting in a balanced IgG1 and IgG2c response (Figure 2h). Importantly, this finding was repeated using another antigen, NP-CGG, supporting the conclusion that differentiation into Th1 cells was independent of IL-12 (J. Mattsson, unpublished observation). An analysis of the phosphorylation of STAT (signal transducer and activator of transcription) proteins in sorted OT-II cells from mice immunized with CT adjuvant demonstrated that both STAT1 and STAT4 signaling pathways were, indeed, active to promote Th1 differentiation even in the absence of IL-12 (Figure 2g). Of note, activation of either STAT1 or STAT4 regulates T-bet expression and hence Th1 differentiation. ${ }^{36,37}$ Both WT and IL-12-/ - mice exhibited comparable STAT1 and STAT4 phosphorylation in OT-II cells (Figure 2g). In fact, all STAT proteins examined displayed an increased level of phosphorylation in CD4 $\mathrm{T}$ cells following immunization with CT adjuvant, typifying differentiation to Th1 (STAT1 and STAT4) Th2 (STAT6), and Th17 (STAT3) cells (J. Mattsson, unpublished observation).

Given that CT also upregulated Rorc mRNA expression in OT-II cells and the production of IL-17 in WT mice, we concluded that the mechanism of action did not appear to restrict differentiation to Th1 or Th2 cells, but Th17 differentiation was also observed. Therefore, we analyzed to what extent the adjuvant effect of CT was dependent on IL-17A following oral immunization with CT, as previously has been reported. $^{29}$ We found no impairment in the generation of

Figure 2 Cholera toxin (CT) promotes T helper type 1 (Th1) responses in the absence of interleukin (IL)-12 and acts as an adjuvant for mucosal IgA immunity independently of IL-17A. Wild-type or IL12p40 - / - (CD45.2 $\left.{ }^{+}\right)$mice were adoptively transferred with highly pure sorted naive CD62L ${ }^{+}$, $\mathrm{CD}^{-} 5^{-}$CD45.1 ${ }^{+}$OT-Il transgenic T cells and immunized intravenously (i.v.) with CT-OVA or ovalbumin (OVA) the next day and killed on day 9 (Supplementary Figure S1). (a) The expansion of OT-II cells in the spleen was determined by flow cytometry. (b,c) Splenocytes were restimulated with OVA for $96 \mathrm{~h}$ and then cultured with phorbol 12-myristate 13-acetate (PMA)/ionomycin and brefeldin for $6 \mathrm{~h}$. Intracellular expression of interferon- $\gamma$ (IFN- $\gamma$ ) and IL-17 was determined by flow cytometry. Gates are set on live CD4 ${ }^{+} \mathrm{Ki} 67^{+} \mathrm{T}$ cells. Representative (b) flow cytometry plot and (c) quantitation. (d) Splenocytes were cultured in triplicates with recall antigen OVA for $96 \mathrm{~h}$, and supernatants were assessed for IFN- $\gamma$ production. (e) Quantitation of IFN $\gamma+$ CD $45.1^{+}$OT-Il cells from the experiment described in b. (f) Real-time PCR (RT-PCR) data for mRNA expression of Tbx21, GATA-3, and Rorc in sorted CD45.1 ${ }^{+}$OT-II T cells from the spleen of unimmunized or CT-OVA-immunized wild-type (WT) or IL-12p40 - / - mice are shown. (g) Sorted naive CD45.1 ${ }^{+}$OT-II transgenic T cells were transferred to WT or IL12p40 - / - CD45.2 ${ }^{+}$mice and the mice were i.v. immunized with CT-OVA. Phosphorylation of STAT1 (pY701) or STAT4 (pY693) in OT-Il cells was determined by flow cytometry at the indicated time points. STAT, signal transducer and activator of transcription. (h) Specific serum IgG1 and IgG2c antibody responses after CT-OVA immunization followed by a booster dose of OVA intraperitoneally (i.p.); $\log _{10}$ titers are given. (i-k) The dependence of IL-17A for mucosal IgA responses was analyzed in WT or IL-17A - / - mice. The mice were immunized perorally (p.o.) with KLH (keyhole limpet hemocyanin) and CT. Specific IgA-producing cells, that is spot-forming cells (SFCs), in the lamina propria (LP) of the small intestine were determined by ELISPOT and values are given as mean SFC $/ 10^{6}$ cells (i). Specific IgA antibody levels in (j) gut lavage or (k) serum IgG1 were determined by enzyme-linked immunosorbent assay (ELISA), and log ${ }_{10}$ titers are given. (I) Splenocytes from WT or IL-17A - / - mice immunized with CT + KLH p.o. were cultured in triplicates with recall antigen KLH for $72 \mathrm{~h}$, and supernatants were collected and assessed for IFN- $\gamma$ (Th1), IL-22, and IL-17A (Th17) production. Statistical significance was calculated using (a-i, j-k) analysis of variance (ANOVA) with Dunnett's posttest or (i, second panel, I) Student's $t$-test. ${ }^{\star} P<0.05$, ${ }^{\star \star} P<0.01$, NS, not significant. Representative data are from at least three experiments giving similar results with five mice in each group or pooled data from three individual experiments (g), and are shown as mean \pm s.d. 
IgA-producing plasma cells in the lamina propria, and correspondingly gut lavage IgA as well as serum IgA and $\mathrm{IgG}_{1}$ responses were unperturbed in IL-17A-deficient mice as compared with WT controls, following oral immunization with CT and KLH (keyhole limpet hemocyanin) (Figure 2i-k). The cytokine production profiles of splenocytes to recall antigen stimulation in vitro following peroral (p.o.) immunizations suggested differentiation to Th1 (IFN- $\gamma$ ) as well as Th17 (IL-22) cells, even in IL-17A-deficient mice (Figure 21). Thus, CT was found to augment CD4 T-cell differentiation to Th1, Th2, as well as Th17 cells in an unbiased manner, with no requirement for IL-12 production by antigenpresenting cells or need for IL-17A for the mucosal adjuvant effect.

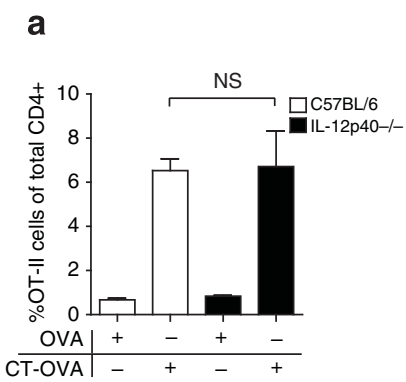

b

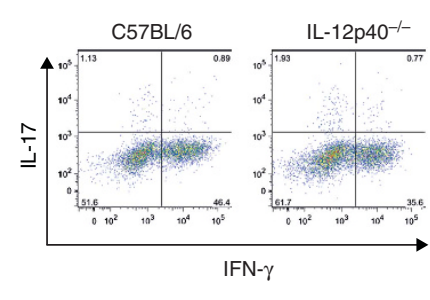

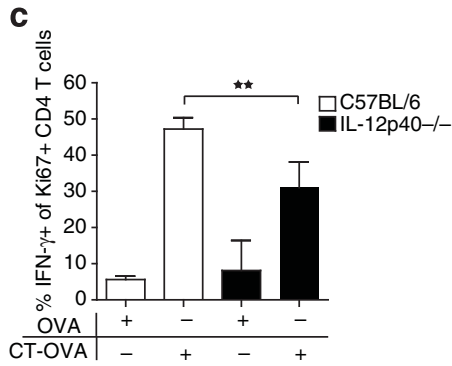

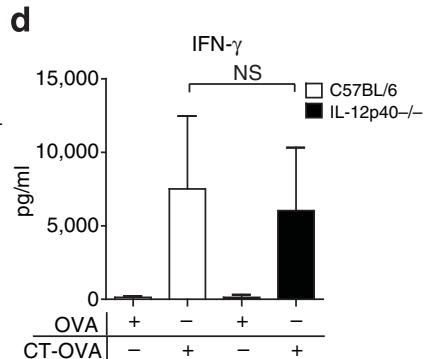

e

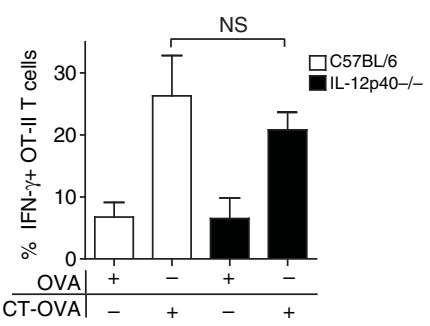

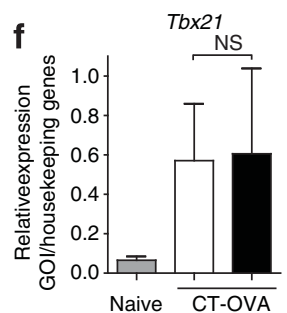
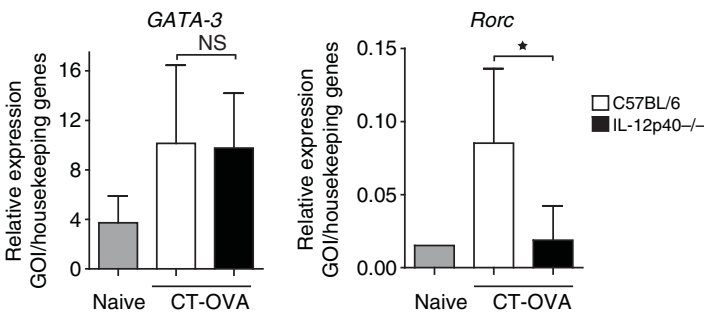

g
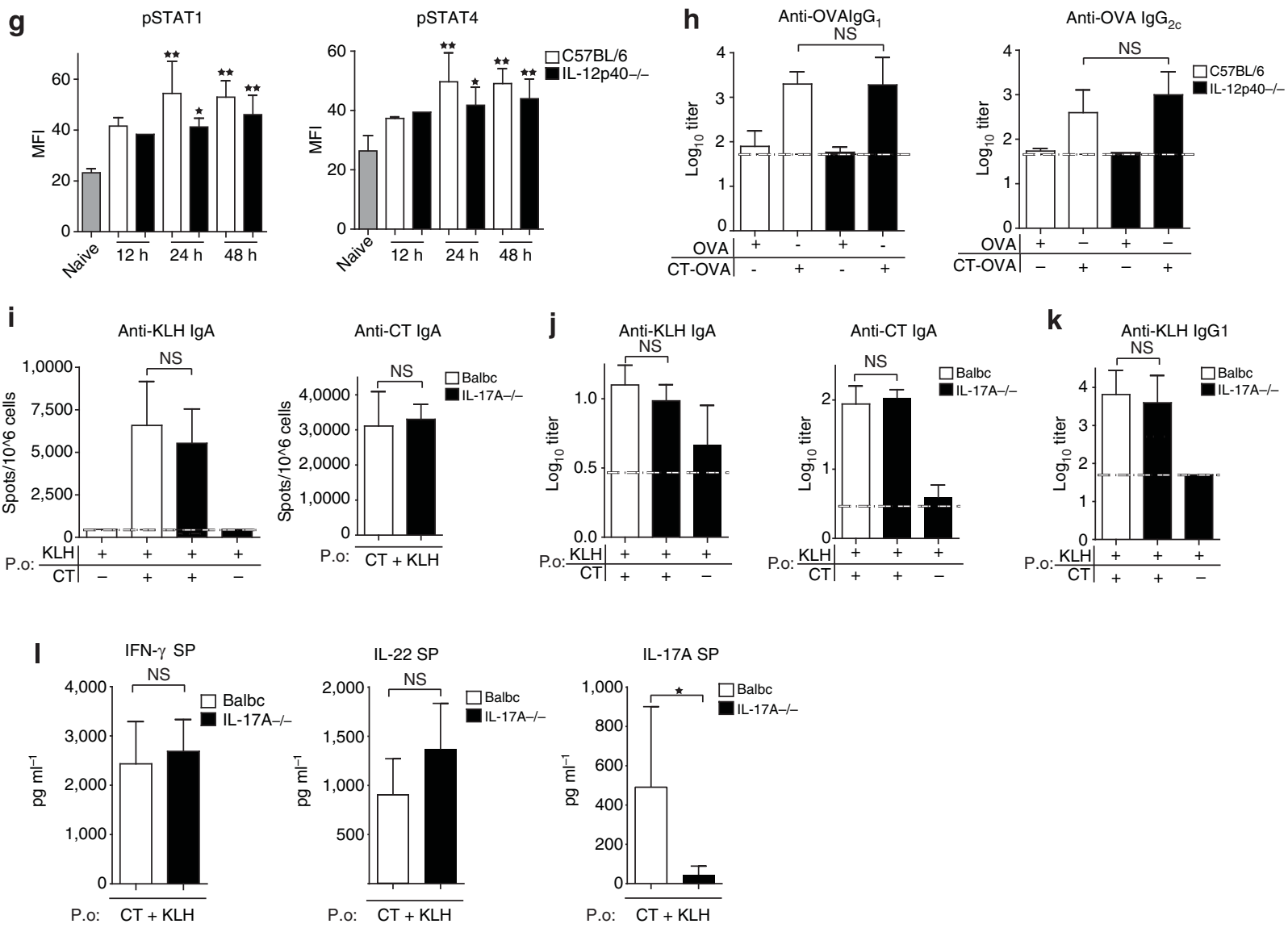
a

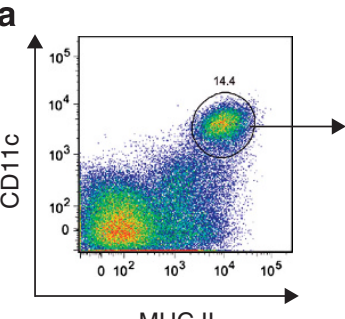

MHC II

C
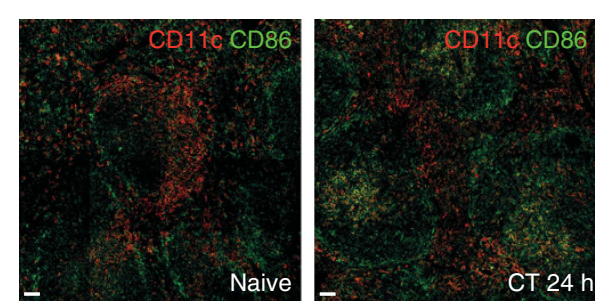

d

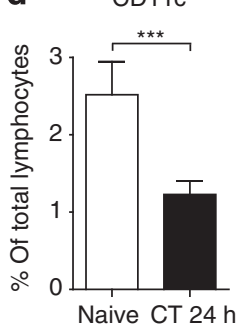

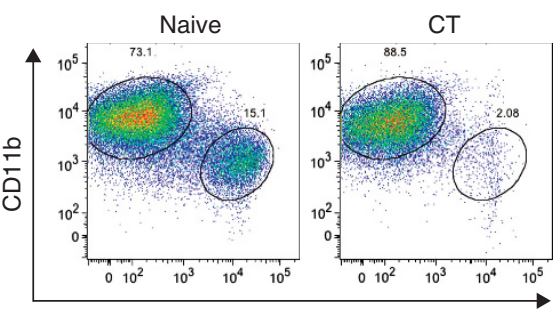

$\operatorname{CD} 8 \alpha$ b $\quad \mathrm{CD} 11 \mathrm{c}^{+} \mathrm{CD} 8 \alpha^{+}$

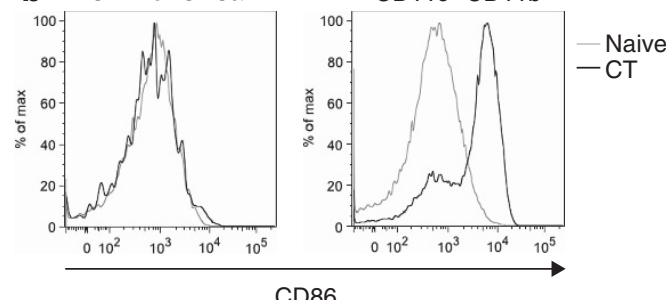

CD86
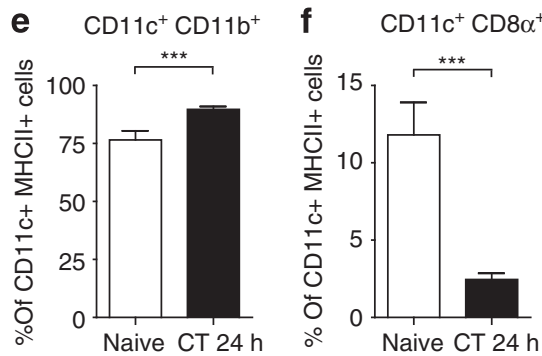

g

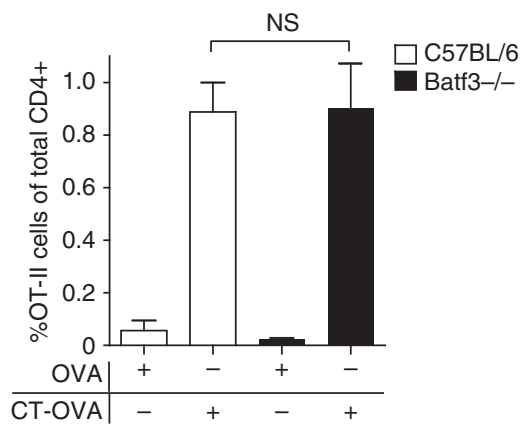

i

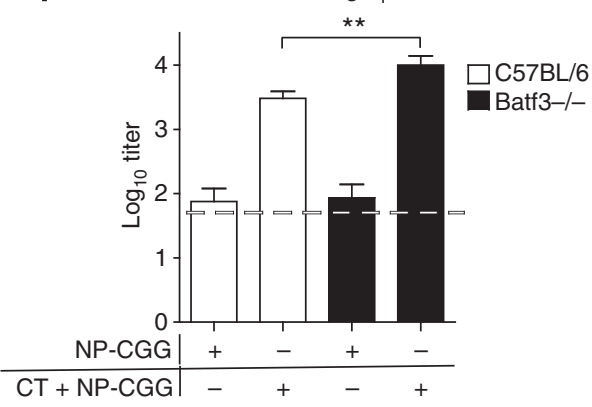

h

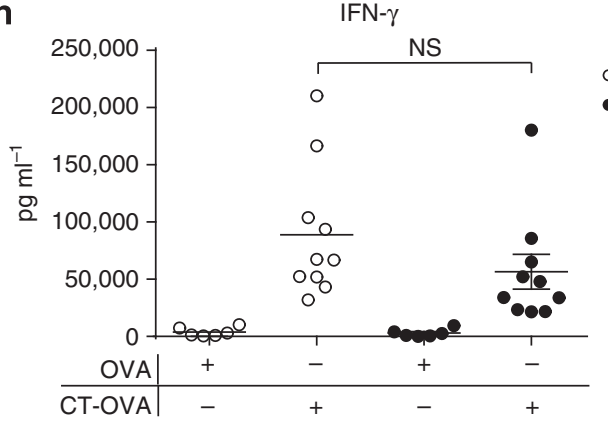

Anti-NP $\operatorname{lgG}_{2 \mathrm{c}}$

j

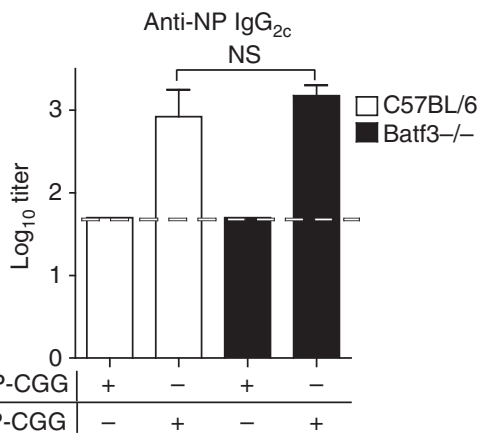

Figure 3 Cholera toxin (CT) selectively activates CD11 $\mathrm{b}^{+}$dendritic cells (DCs) and depletes the CD8 $\alpha^{+}$subtype that is dispensable for the adjuvant effect of CT. (a) Flow cytometry analysis of CD11 ${ }^{+}$and CD8 $\alpha^{+}$in $\mathrm{CD}_{11 \mathrm{c}}{ }^{+}$and $\mathrm{MHC} \mathrm{I}^{+}$gated DCs in the spleen of naive mice or mice immunized intravenously (i.v.) with CT $24 \mathrm{~h}$ before analysis. (b) CD86 expression in CD11 b ${ }^{+}$or CD8 $\alpha^{+}$DCs in naive (gray line) or CT-immunized mice (black line). (c) Spleen sections from naive or CT-immunized mice were labeled with anti-CD11c (red) and anti-CD86 (green) mAbs to visualize activated DCs migrating into the T-cell zone. (d-f) Quantification of the data generated in $\mathbf{a}$. (g,h) Wild-type (WT) or Batf3 $-/-\mathrm{CD}_{4} .2^{+}$mice were adoptively transferred with sorted naive $\mathrm{CD}_{22} \mathrm{~L}^{+}, \mathrm{CD} 25^{-} \mathrm{CD} 45.1^{+}$OT-II transgenic T cells and immunized i.v. with ovalbumin (CT)-OVA. On day 9, the expansion of OT-II cells was determined in the spleen. (g) Splenocytes were cultured in triplicates with recall antigen OVA for $96 \mathrm{~h}$ and supernatants were assessed for interferon- $\gamma(\mathrm{IFN}-\gamma)$ production (h). (i,j) The adjuvant effect on antibody responses was determined after i.v. priming immunizations with NP-CGG together with or without CT followed by an intraperitoneal (i.p.) booster of NP-CGG. Specific serum IgG1 or IgG2c responses are given as log ${ }_{10}$ titers on day 18 after priming. Statistical significance was calculated using $(\mathbf{g}-\mathbf{j})$ analysis of variance (ANOVA) with Dunnett's posttest or (d-f) Student's $t$-test. ${ }^{\star \star} P<0.01,{ }^{* \star} P<0.001$, NS, not significant. Representative data are from $(\mathbf{i}, \mathbf{j})$ two or $(\mathbf{a}-\mathbf{h})$ three experiments giving similar results with $(\mathbf{a}-\mathbf{f})$ three or $(\mathbf{g}-\mathbf{j})$ five mice in each group. Data are shown as mean \pm s.d.

Immunization with CT depletes CD8 $\alpha^{+}$DCs and selectively induces maturation of the CD11b ${ }^{+}$DCs, blocking DC functions for several days

Previous studies have provided conflicting data on the role of $\mathrm{CD} 8 \alpha^{+}$DCs and the adjuvant effect of CT. ${ }^{14,23}$ Although
$\mathrm{CD} 8 \alpha^{+}$DCs were critical for the ability of CT to enhance CD8 T-cell responses, it blocked IRF8 functions and inhibited differentiation of CD8 $\alpha^{+}$DCs. ${ }^{14,23}$ Therefore, we next asked whether CD $8 \alpha^{+}$DCs were needed for the adjuvant effect of CT on CD4 T-cell priming and antibody production. In agreement 

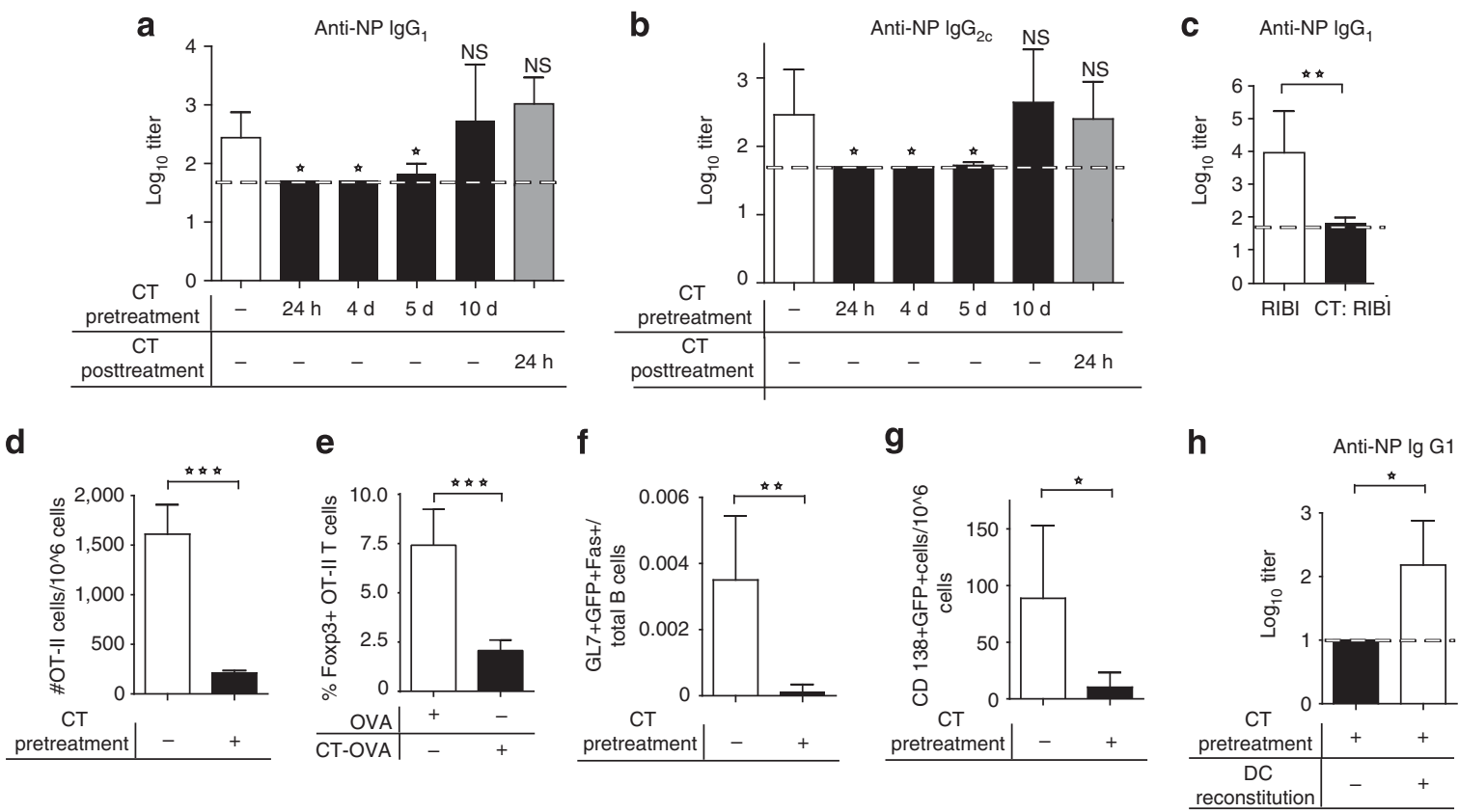

Figure 4 Immunization with cholera toxin (CT) adjuvant blocks responses to subsequent immunizations with other adjuvants. (a,b) Mice were given CT intravenously (i.v.) $24 \mathrm{~h}$, and 4,5 , or 10 days before or $24 \mathrm{~h}$ after priming with NP-CGG together with CTA1-DD adjuvant followed by a booster with NP-CGG on day 10. Serum was collected on day 18 and $N P$-specific $\lg _{1}$ or $\lg _{2 c}$ were measured using enzyme-linked immunosorbent assay (ELISA) and given as $\log _{10}$ titers. (c) Mice were given CT i.v. followed by priming $24 \mathrm{~h}$ later with NP-CGG together with Ribi adjuvant and boosted with NP-CGG on day 10 . NPspecific serum $\log _{10}$ titers are given. (d) CD4 T-cell priming was blocked after CT immunization. Recipient mice $\left(C D 45.2^{+}\right)$were given carboxyfluorescein succinimidyl ester (CFSE)-labeled CD45.1 ${ }^{+}$OT-II transgenic ovalbumin (OVA) T cells by adoptive transfer and pretreated with CT i.v. On day 2, mice were immunized i.v. with CTA1-OVA-DD and killed on day 6 . The number of OT-II cells from the spleen was determined by flow cytometry. (e) CD45.2 ${ }^{+}$mice were adoptively transferred with sorted naive $\mathrm{CD}_{22} \mathrm{~L}^{+}, \mathrm{CD} 25^{-} \mathrm{CD} 45.1^{+} \mathrm{OT}-\mathrm{Il}$ transgenic $\mathrm{T}$ cells and immunized i.v. with CT-OVA or OVA the next day and killed on day 9; Foxp3 + regulatory T cells (Tregs) among OT-II CD4 T cells are given. $(\mathbf{f}, \mathbf{g})$ Germinal center formations were inhibited by i.v. CT immunization. Mice were given $1 \times 10^{5} \mathrm{NP}$-specific GFP ${ }^{+} \mathrm{B}$ cells by adoptive transfer and immunized i.v. with CT $24 \mathrm{~h}$ before subsequent priming with NP-CGG with the CTA1-DD adjuvant. The number of $(\mathbf{f}) \mathrm{GL}^{+}$germinal center B cells and (g) $\mathrm{CD} 138^{+}$plasma cells in the spleen was determined by flow cytometry 12 days after priming. (h) Reconstituting CT pretreated mice with dendritic cells (DCs) partially restored the ability to respond to subsequent priming immunizations. Mice were immunized i.v. with CT and on day 4 these mice were reconstituted with $5 \times 10^{6}$ freshly isolated MACS-sorted CD $11 \mathrm{c}^{+}$enriched DCs from Flt3Ltreated donor mice. At $1 \mathrm{~h}$ after reconstitution, mice were immunized with NP-CGG plus CTA1-DD adjuvant and boosted on day 10 with NP-CGG intraperitoneally (i.p.). Serum was collected on day 18 and NP-specific $\lg _{1}$ antibodies were measured using ELISA, and given as log ${ }_{10}$ titers. Statistical significance was calculated using $(\mathbf{a}, \mathbf{b})$ analysis of variance (ANOVA) with Dunnett's posttest or $(\mathbf{c}-\mathbf{h})$ Student's $t$-test. ${ }^{*} P<0.05$, ${ }^{\star \star} P<0.01,{ }^{\star * \star} P<0.001$, NS, not significant. Data are representative of two identical experiments with five mice per group and are shown as mean \pm s.d.

with earlier studies, we found that the frequency of $\mathrm{CD} 8 \alpha^{+}$ DCs among CD11 $\mathrm{c}^{\text {hi }}$ MHC II ${ }^{\text {hi }}$ cDCs was reduced by $>90 \%$ $24 \mathrm{~h}$ after CT treatment (Figure 3a,f). ${ }^{23}$ In contrast, CD11b ${ }^{+}$ DC frequencies were unaltered and these cells were activated and had upregulated CD86 (Figure 3a,b,e). No macrophages or monocytes were detected in the gated DC population (Supplementary Figure S2). Tissue sections of the spleen revealed that a large proportion of all DCs had migrated from the marginal zone into the T-cell zone (Figure 3c). To further document that $\mathrm{CD} 8 \alpha^{+}$DCs were dispensable for the adjuvant effect, we immunized Batf3 - / - mice with antigen and CT adjuvant, as these mice completely lack the $\mathrm{CD} 8 \alpha^{+}$DC subset. ${ }^{38}$ We found an intact adjuvant effect with comparable expansion and production of IFN- $\gamma$ by OT-II cells in Baft3 -1 - and WT mice and similar or slightly elevated specific antibody titers following immunization, arguing in favor of the fact that CT required $\mathrm{CD}_{11 \mathrm{~b}}{ }^{+}$DCs for the adjuvant effect (Figure 3g-j). However, unexpectedly we found that immunizations with CT-adjuvant i.v. completely blocked all attempts to subsequently immunize with Ribi or CTA1-DD adjuvants. ${ }^{39}$ Indeed, CT pretreatment eliminated the ability to prime $\mathrm{CD} 4 \mathrm{~T}$ cells or activate specific $\mathrm{B}$ cells (Figure 4a-g). This blocking effect persisted for many days and normal responsiveness was not regained until 10 days after CT adjuvant administration (Figure 4a,b). The unresponsiveness did not appear to be induced by Foxp $3^{+}$regulatory $\mathrm{T}$ cells as the frequency was reduced in mice given CT (Figure 4e). In contrast, if CT was given after CTA1-DD (or Ribi), no negative effect on the ability to respond to Ag (NP-CGG) was observed, suggesting that CT prevented a crucial early event of the immune response (Figure 4a,b). Strikingly though, the transfer of freshly isolated highly enriched splenic CD11 chigh DCs into CT pretreated recipient mice restored responsiveness to subsequent immunizations, identifying that resting DCs were critical for the adjuvant effect (Figure 4h). Hence, as CD8 $\alpha^{+}$ DCs were dispensable, we concluded that the adjuvant effect of $\mathrm{CT}$ relied exclusively on $\mathrm{CD}_{11 \mathrm{~b}^{+}}$classical DCs in vivo.

The adjuvant function of $\mathrm{CT}$ is critically dependent on the expression of $\mathrm{Gs} \alpha$ in $\mathrm{CD} 11 \mathrm{c}^{+} \mathrm{DCs}$

To further demonstrate that $\mathrm{CD}_{11 \mathrm{~b}^{+}} \mathrm{CD} 1 \mathrm{c}^{+}$cells and, in particular, the ADP-ribosylating effect of CTA1 subunit on 
membrane Gs $\alpha$, was the key target in these cells for the adjuvant effect in vivo, we developed a mouse model in which DCs were defective in the Gs $\alpha$ membrane protein. These conditional knockout mice expressed the Cre recombinase under the CD11c promoter and had a floxed Gs $\alpha$ gene, thus lacking Gs $\alpha$ specifically in CD11c ${ }^{+}$cells. ${ }^{40,41}$ Hence, the ADP-ribosylation of $\mathrm{Gs} \alpha$ by $\mathrm{CT}$ and the subsequent activation of adenylate cyclase and increased intracellular cAMP levels specifically in DCs could not occur in these mice. However, all other potential target cells were unmodified and membrane Gs $\alpha$ could be activated by the CT adjuvant. ${ }^{42,43}$ Absence of Gs $\alpha$ (GNAS) expression in DCs was confirmed by sorting cells from the spleens of WT and CD11c-Cre Gs $\alpha$ mice and measuring levels of Gs $\alpha$ mRNA (Figure 5a). Interestingly, upon CT administration, we found that the $\mathrm{CD} 8 \alpha^{+}$DC subset was retained in the CD11c-cre Gs $\alpha$ mice, suggesting that depletion of this subset in WT mice was, indeed, dependent on ADPribosylation of Gs $\alpha$. Moreover, these mice also failed to upregulate $\mathrm{CD} 86$ expression on $\mathrm{CD} 11 \mathrm{~b}^{+} \mathrm{DCs}$, in contrast to that seen in WT littermate controls (Figure $\mathbf{5 b}-\mathbf{d}$ ). Next, we adoptively transferred sorted naive OT-II CD4 T cells to the CD11c-Cre Gs $\alpha$ mice to evaluate whether the lack of Gs $\alpha$ in $\mathrm{CD}_{11 \mathrm{c}^{+}}{ }^{\mathrm{DC}}$ affected CD4 T-cell priming. Strikingly, the transgenic mice completely failed to support the expansion of OT-II $\mathrm{T}$ cells in response to CT-OVA, demonstrating the critical requirement for Gs $\alpha$ specifically in $\mathrm{CD}_{11} \mathrm{~b}^{+}$DCs (Figure 5e). In addition, upon adoptive transfer of $\mathrm{GFP}^{+} \mathrm{NP}$ specific transgenic B cells, the CD11c-Cre Gs $\alpha$ mice failed to support the development of germinal centers following i.v. or i.n. immunizations with NP-CGG together with CT (Figure 5f,h). Interestingly NP-specific extrafollicular plasma cells were formed in the spleen but not in the mediastinal lymph node of the CD11c-Cre Gs $\alpha$ mice, suggesting that the specific plasma cell responses in the spleen were relatively $\mathrm{T}$-cell independent (Figure 5f,h). Furthermore, antibody titers were dramatically reduced in the transgenic mice as compared with WT mice (Figure 5i,j). Importantly, when immunizing with the unrelated Ribi adjuvant, the CD11c-Cre Gs $\alpha$ mice were perfectly able to mount a strong antibody response, demonstrating that these mice showed unimpaired responsiveness to other adjuvants, in this case dependent on TLR activation (Figure 5k). Together, these findings clearly demonstrate the importance of the Gs $\alpha$-activation pathway for the adjuvant effect of CT. Therefore, we can conclude that of the many modulatory effects of CT on several cell types in secondary lymphoid tissues, we have unequivocally identified that the target cells for the adjuvant effect of CT are the CD11 $\mathrm{b}^{+}$ $\mathrm{CD}_{11 \mathrm{c}^{+}} \mathrm{DCs}$, and that the adjuvant mechanism is dependent on ADP-ribosylation of the membrane Gs $\alpha$ protein.

\section{DISCUSSION}

In this study, we conclude that CT efficiently enhanced priming of Th1, Th2, as well as Th17 responses in an unbiased manner. Similar findings were recorded in both spleen and draining lymph nodes after parenteral and mucosal immunizations, respectively. Furthermore, CD4 T-cell priming and IFN- $\gamma$ production were unaffected in IL-12-deficient mice, demonstrating that the adjuvant effect was independent of IL-12, and this was also supported by our findings of upregulated STAT1 and STAT4 signaling in primed T cells in these mice. Moreover, we found that CT depleted CD $8 \alpha^{+}$DCs and the adjuvant effect was unperturbed in Batf3-/ - mice (lacking CD8 $\alpha^{+}$DCs). Therefore, the $\mathrm{CD} 11 \mathrm{~b}^{+} \mathrm{DC}$ subset is the critical target population for the adjuvant effect of CT. Most importantly, we found that the adjuvant mechanism was critically dependent on ADP-ribosylation of Gs $\alpha$, as discerned from experiments showing lack of adjuvant effect in mice selectively depleted of Gs $\alpha$ in CD $11 c^{+}$cells. Hence, this is the first study to identify the key target mechanism for the adjuvant effect of CT and to link this effect to the $\mathrm{CD} 11 \mathrm{~b}^{+}$DC subset and the membrane Gs $\alpha$ target protein.

Whether increases in intracellular cAMP are necessary for the adjuvant effect is still poorly understood. For example, the CTA1-DD adjuvant, selectively exploiting the CTA1 enzyme, exerts comparable adjuvanticity to that of intact CT, but cAMP levels of the targeted cells are unaffected by this adjuvant. ${ }^{31}$ Therefore, it must be noted that whereas many studies have associated the adjuvant effect of CT with increases in intracellular cAMP, such downstream effects of ADP-ribosylation of Gs $\alpha$ may not be involved in the adjuvant effect. Moreover, previous studies showed that increased cAMP levels could block Th1 differentiation and IFN- $\gamma$ production by inhibiting IL-12 production via an IRF8-dependent mechanism that led to death in T. gondii infection. ${ }^{23,24,44,45}$ However, in this study, we clearly demonstrated that CT treatment effectively blocks all attempts of subsequent priming of CD4 T cells; that is, not only Th1 but also Th2 and Th17 responses. Therefore, the reported lethal outcome of T. gondii infection in CT-treated mice may rather have reflected a lack of T-cell priming ability rather than revealing a specific inability to form Th1 responses following CT treatment. This interpretation is further supported by our finding that IL-12 was completely dispensable for priming of Th1 responses and the adjuvant effect.

How CT induces Th1 differentiation in the absence of IL-12 is poorly known. Our study is incomplete in that we did not investigate other factors known to be involved in Th1 differentiation, such as IL-18, IL-27, type I IFNs, or Notch ligands. ${ }^{46-49}$ However, although IL-27, and possibly also IL-18, appears to exert effects on Th1 differentiation only in the presence of IL-12, a direct dependence on these factors is unlikely. ${ }^{50-52}$ Somewhat at conflict with this interpretation, though, is the fact that we found poor Th1-adjuvant function of CT in IL-18-deficient mice following oral immunization with Helicobacter pylori antigens, arguing in favor of an involvement of IL-18 for CT-promoted Th1 differentiation. ${ }^{53}$ Moreover, although the Notch ligand Dll4 has been shown to be able to drive Th1 differentiation in some models, its role for the adjuvant function of CT has previously been dismissed by other investigators. ${ }^{54,55} \mathrm{With}$ regard to type I IFNs we have found that type I IFN receptor-deficient mice demonstrated an intact adjuvant effect of CT with comparable increases in specific IgG1 and IgG2c serum antibodies to those in WT mice, arguing 
a

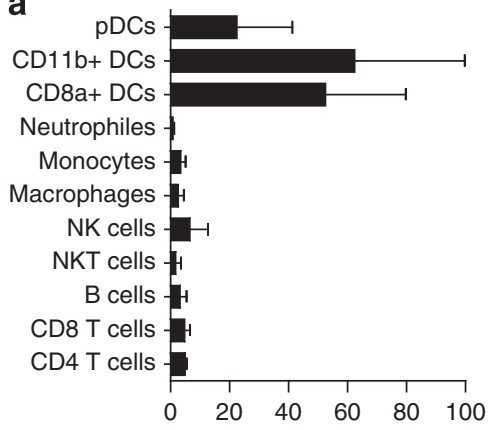

Relative expression WT/CD11c-Cre Gs $\alpha$ b

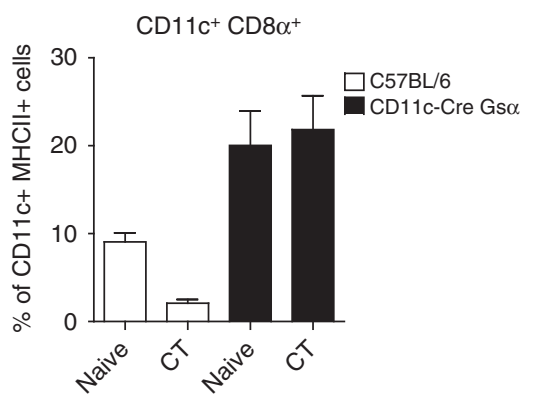

C

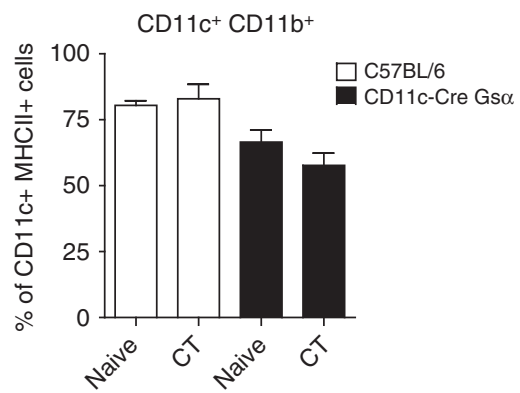

d
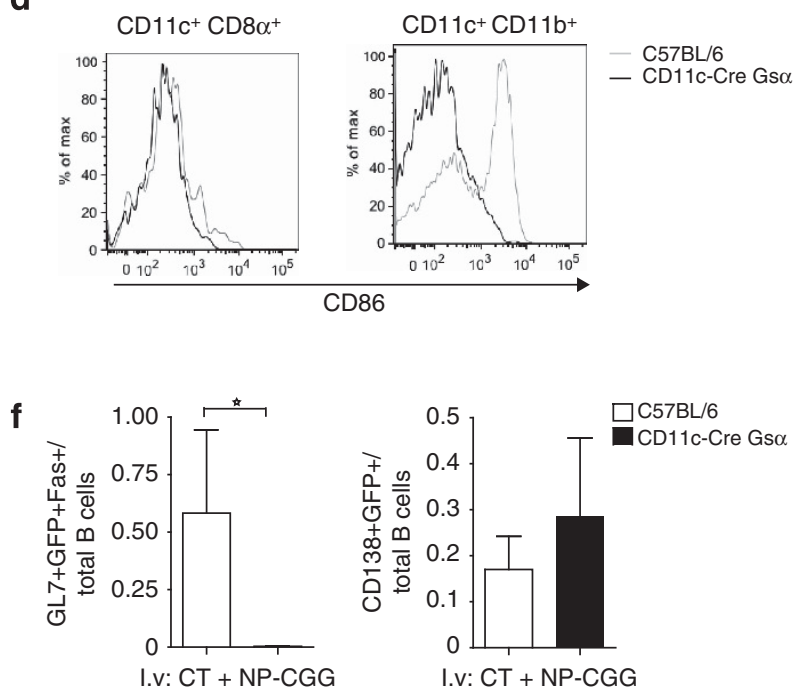

h

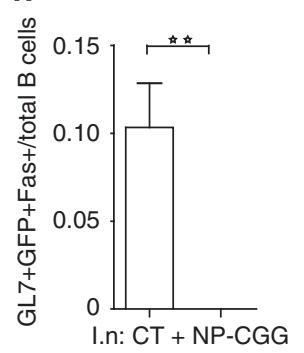

i

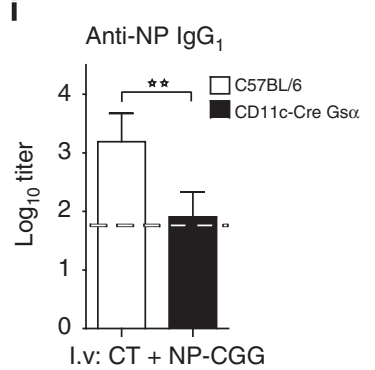

e

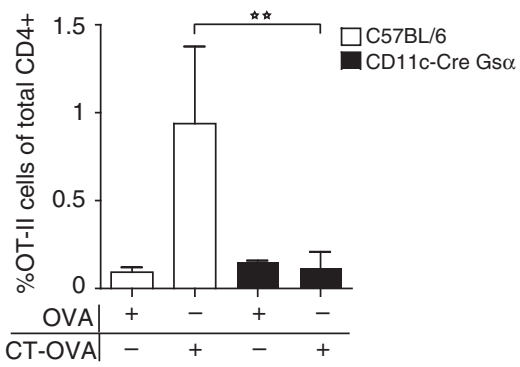

g
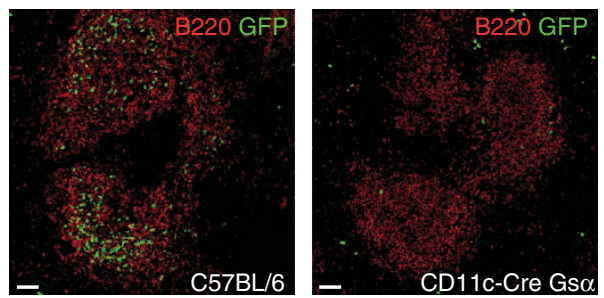

j

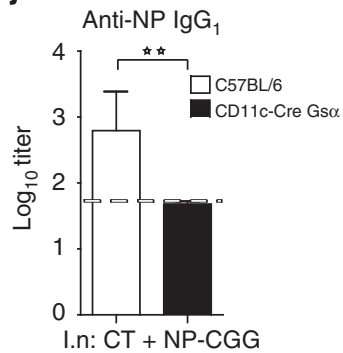

k

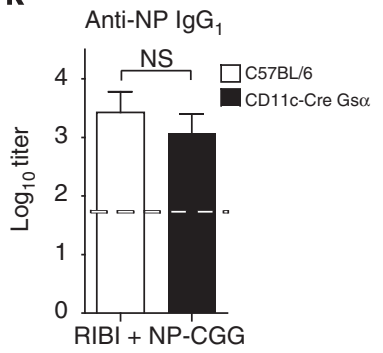

Figure 5 Gs $\alpha$ expression in $C D 11 c^{+}$dendritic cells (DCs) is required for the adjuvant function of cholera toxin (CT). (a) Expression of Gs $\alpha$ mRNA in fluorescence-activated cell-sorted (FACS) cell populations. Live cells were gated as follows: B cells (CD3-CD19 $\left.{ }^{+}\right), C^{-} 4^{-}$cells $_{(C D 19}{ }^{-}$CD3 ${ }^{\text {hi }}$ CD4 ${ }^{+}$),

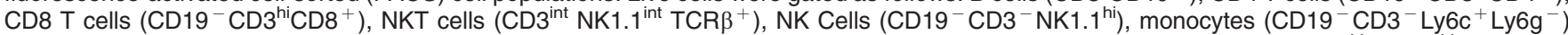
neutrophils $\left(\mathrm{CD} 19^{-} \mathrm{CD}^{-} \mathrm{Ly6g}^{+} \mathrm{CD}_{11 b^{+}}\right)$, macrophages (CD19 $\left.{ }^{-} \mathrm{CD} 3^{-} \mathrm{CD} 11 \mathrm{c}^{-} \mathrm{F} 4 / 80^{+}\right) \mathrm{CD}^{-} \alpha^{+} \mathrm{DCs}\left(\mathrm{CD} 19^{-} \mathrm{CD}^{-}{ }^{-} \mathrm{CD} 11 \mathrm{c}^{\mathrm{hi}} \mathrm{MHCll}^{\mathrm{hi}} \mathrm{CD}^{-} \alpha^{+}\right)$, CD11b ${ }^{+}$DCs $\left(C D 19^{-}\right.$CD3 $^{-}$CD11 $c^{\text {hi }}$ MHCII ${ }^{\text {hi }}$ CD11 $\left.b^{+}\right)$, and pDC (CD19- CD3 ${ }^{-}$CD11 $c^{\text {int }}$ MHCII $^{\text {int }}$ PDCA-1 $\left.{ }^{+}\right)$. NK cell, natural killer cell; NKT cell, natural killer T cell; pDC, plasmacytoid DC. (b,c) Transgenic CD11c-Cre Gs $\alpha$ - or wild-type (WT) mice were given CT $24 \mathrm{~h}$ before analysis and the frequency of (b) CD8 $\alpha^{+}$and (c) CD11 b ${ }^{+}$DCs was monitored in the spleen (gating as in Figure 3a). (d) CD86 expression on CD8 $\alpha^{+}$and CD11b ${ }^{+}$DCs from CT-immunized WT (gray line) or CD11c-Cre Gs $\alpha$ mice (black line). (e) WT and CD11c-Cre Gs $\alpha$ mice $\left(C D 45.2^{+}\right.$) were given sorted naive $\mathrm{CD}_{2} \mathrm{~L}^{+}, \mathrm{CD} 25^{-} \mathrm{CD} 45.1^{+}$OT-II transgenic T cells by adoptive transfer on day 1 and subsequently immunized intravenously (i.v.) with ovalbumin (OVA) or CT-OVA the next day. The frequency of OT-II cells in the spleen of immunized mice was determined by flow cytometry. (f-h) WT and CD11c-Cre Gs $\alpha$ mice were given $1 \times 10^{5} \mathrm{NP}$-specific GFP ${ }^{+}$B cells by adoptive transfer and immunized (f,g) i.v. or (h) intranasally (i.n.) with NP-CGG with CT adjuvant . The number of $\mathrm{GL}^{+}$germinal center B cells, or $\mathrm{CD} 138^{+}$plasma cells in spleen or the mediastinal lymph node respectively were determined by flow cytometry 12 days after immunization. Representative micrographs of spleen sections are shown in $\mathbf{~ g . ~ ( i - k ) ~ W T ~ o r ~ C D 1 1 c - C r e ~ G s ~} \alpha$ mice were immunized i.v. or i.n. using CT + NP-CGG or intraperitoneally (i.p.) using the Ribi adjuvant + NP-CGG as indicated, and 10 days later the mice were boosted. Serum was collected at day 18 , and NP-specific $\operatorname{lgG}_{1} \log _{10}$ titers are given. Statistical significance was calculated using (e) analysis of variance (ANOVA) with Dunnett's posttest or (f, $\mathbf{h}-\mathbf{k})$ Student's $t$-test. ${ }^{\star} P<0.05$, ${ }^{\star *} P<0.01$, NS, not significant. Data are representative of two identical experiments with (a) one, $(\mathbf{b}-\mathbf{d}, \mathbf{f}-\mathbf{h})$ three, or $(\mathbf{e}, \mathbf{i}-\mathbf{k})$ five mice per group. Data are shown as mean \pm s.d. Scale bars $=50 \mu \mathrm{m}$. 
against a role for type I IFNs in CT-mediated Th1 differentiation (J. Mattsson, unpublished results). In addition, this study cannot completely rule out the direct effects of CT on CD4 $\mathrm{T}$ cells, although we failed to document an adjuvant effect in mice with $\mathrm{CD}_{11 \mathrm{c}^{+}}$cells lacking Gs $\alpha$, arguing in favor of the fact that the adjuvant effect is exclusively dependent on DCs. However, it is conceivable that CT could have affected cAMP levels in primed CD4 $\mathrm{T}$ cells, thereby supporting an IL-12independent Th1 differentiation. The CREB (cAMP-responsive element-binding protein) can upregulate STAT1 signaling and, hence, allow Th1 differentiation independently of IL- $12 .^{26}$ Future studies will address this possibility. We favor, though, the concept that $\mathrm{CT}$ adjuvant acted through $\mathrm{CD} 11 \mathrm{~b}^{+} \mathrm{DCs}$, in particular as CD4 $\mathrm{T}$-cell priming in response to Ribi adjuvant was intact in mice lacking Gs $\alpha$ in $\mathrm{CD} 11 \mathrm{c}^{+}$cells.

Importantly, we observed an activation of STAT1, STAT4, STAT6, and STAT3, representing Th1, Th2, and Th17 responses, respectively, in primed CD4 $\mathrm{T}$ cells after immunizations with the CT adjuvant. This speaks in favor of the fact that CT is not selectively affecting the priming event, rather CT promotes augmented priming of multiple CD4 effector populations. Indeed, this also involves priming of Foxp3 ${ }^{+}$ $\mathrm{T}$ cells and other regulatory CD4 T cells producing IL-10, that is, type 1 regulatory T cells. ${ }^{11}$ Given that STAT4 most often is linked to IL-12 signaling whereas STAT1 is primarily activated by IFN- $\gamma,{ }^{36,37}$ the observed induction of both STAT1 and STAT4 in WT and IL-12p40-/ - mice was surprising. However, as activation of STAT4 can occur in the absence of IL12 , this offers a possible explanation to the CT effect on Th1 differentiation ${ }^{52}$ and supports our interpretation that CT enhances CD4 T-cell priming in an unbiased manner. What function IL-18 could have in CT-mediated Th1 differentiation awaits to be investigated, but CT is known to increase IL- $1 \beta$ production, which is a Caspase-1-dependent function, in both macrophages and DCs. ${ }^{33,56}$ Although the IL- 18 receptor signals through MyD88, we have preliminary data to indicate that the Th1-stimulating effect of CT is, indeed, intact in MyD88 - / mice (N. Lycke, unpublished data) that would disagree with a direct dependence on IL-18 for the adjuvant effect.

In agreement with other studies, we found that $\mathrm{CT}$ also promotes Th17 differentiation as assessed by enhanced Rorc gene expression, STAT3 signaling, and IL-17 production..$^{22,27-29}$ Because Th17 cells were reported critical for follicular helper T cell development in PPs and mice deficient in Th17 cells or IL-17 had reduced mucosal IgA responses following intranasal or oral immunization with CT adjuvant, we asked whether IL-17A was required for the adjuvant effect of CT. ${ }^{29,30}$ Contrary to Datta et al. ${ }^{29}$ we observed an intact oral mucosal IgA adjuvant effect of CT in IL-17A - / - mice, and, hence, no dependence on IL-17A could be detected. The reason for these discrepant results is not known, but it is possible that IL-17A - / - mice have a reduced capacity to develop follicular helper T cell in PPs, in agreement with the observations made by Hirota et al., ${ }^{30}$ and, therefore, were exhibiting weaker mucosal IgA responses to OVA as compared with the stronger immunogen KLH used in the present study. But, notwithstanding this, our results clearly support that the adjuvant effect of CT itself can be independent of IL-17A. In fact, our study favors the fact that Th17 cells can also be induced in IL-17A-deficient mice as we observed strong IL-22 increases in response to recall antigen challenge of splenocytes from orally CT adjuvant-immunized mice. Hence, in analogy with the study by Hirota et al., ${ }^{30}$ we hypothesize that Th17 cells were stimulated in the PPs, even in IL-17A-deficient mice, that subsequently promoted IgA B-cell differentiation in response to oral KLH plus CT. Of note, IL-17A would thus not be an essential component in IgA B-cell differentiation in PPs, rather IL-21 could fulfill this critical function. ${ }^{57}$

CT was found to deplete CD $8 \alpha^{+}$cDCs, in agreement with previous studies. ${ }^{23}$ We observed a dramatic reduction of $\mathrm{CD} 8 \alpha^{+}$cDCs in the spleen after CT administration. In contrast, $\mathrm{CD}_{11 b^{+}} \mathrm{cDCs}$ numbers were not reduced, but rather this DC subset exhibited clear signs of activation (CD86 expression was increased), and migrated into the T-cell zone, leaving few, if any, immature DCs that could take up and present antigen. ${ }^{58,59}$ In accordance, we failed to prime additional naive $\mathrm{T}$ cells for several days after $\mathrm{CT}$ administration. Because CT caused a loss of CD $8 \alpha^{+}$DCs in WT mice, we could conclude that $\mathrm{CD} 11 \mathrm{~b}^{+}$DCs were the crucial subset of DCs that were targeted by $\mathrm{CT}$ and responsible for the adjuvant effect. This was also confirmed in Batf3-/- mice that lacked $\mathrm{CD} 8 \alpha^{+}$DCs but still exhibited intact CT-adjuvant priming of CD4 T cells. The CD8 $\alpha^{+}$DC-depleting effect of CT was most probably a direct effect of the toxin and ADP-ribosylation of cell membrane Gs $\alpha$, as the CD8 $\alpha^{+}$DCs in the CD11c-Gs $\alpha$ deficient mice were not depleted.

We have previously shown that CT exerts its adjuvant effect at mucosal membranes by directly modulating the DC population. This was demonstrated by selectively depleting GM1 ganglioside, the receptor for CTB (cholera toxin B subunit), from all hematopoietic cells in a bone marrow chimeric model that failed to exhibit gut IgA-adjuvant effects of CT. ${ }^{32}$ Several other studies, including our own, have identified DC to be a key population for the adjuvant effect, but also other potential antigen-presenting cells were shown to be affected by CT. ${ }^{3,10,12,13,44,60-64}$ This study extends our knowledge about which subset of DC is needed, that is, the CD11 ${ }^{+} \mathrm{CD} 8 \alpha^{-} \mathrm{DCs}$, and identifies that Gs $\alpha$ is absolutely required for the adjuvant effect. Furthermore, we conclude that the adjuvant functions of CT can be completely independent of IL-12 and IL-17A. Thus, we provide important new information on the mechanism of action of $\mathrm{CT}$, and potentially other ADP-ribosylating toxin adjuvants that help accommodate and explain the large number of conflicting reports in the past. We conclude that CT adjuvant acts through membrane Gs $\alpha$ in DCs and is a strong enhancer of CD4 T-cell priming, resulting in substantial generation of Th1, Th2, and Th17 cells in an unbiased manner.

\section{METHODS}

Mice and immunizations. C57BL/6 mice were obtained from Taconic (M\&B, Bomholt, Denmark). OT-II T cell receptor transgenic mice, Batf3 - / -, CD11c-Cre Gs $\alpha$, IL12p40-/- mice on the B6 
background, and $\mathrm{B} 1-8^{\text {hi }}$ mice bred to B6-GFP mice ${ }^{65,66}$ and IL-17A - / - mice on Balbc background ${ }^{67}$ were maintained and bred in ventilated cages at the Laboratory for Experimental Biomedicine, University of Gothenburg (Gothenburg, Sweden). The Cre-lox Gs $\alpha$ deficient $\mathrm{CD} 11 \mathrm{c}$ mice were generated by breeding Cre-CD11c mice with mice with floxed Gs $\alpha$ genes. ${ }^{40,41}$ Mice were age and sex matched and maintained under specific pathogen-free conditions. Mice were immunized with 1 (i.v. or i.n.) or $10 \mu \mathrm{g}$ (p.o.) CT (List Biological Laboratories, Campbell, CA), $1 \mu \mathrm{g}$ CT-OVA, $1 \mu \mathrm{g}$ CTB-OVA, $50 \mu \mathrm{g}$ endotoxin-low OVA containing $6 \mathrm{EU} \mathrm{mg}^{-1}$ of protein or $500 \mu \mathrm{g} \mathrm{KLH}$, $5 \mu \mathrm{g}$ NP-CGG (Biosearch Technologies, Petaluma, CA), $5 \mu \mathrm{g}$ CTA1DD, or with the Ribi adjuvant (MPL + TDM + CWS Adjuvant System, M6661; Sigma-Aldrich, St Louis, MO) prepared according to the manufacturer's instructions. Formulations were given i.v., i.n., or p.o. in 200,20 , or $500 \mu \mathrm{l}$ in phosphate-buffered saline (PBS; with $3 \%$ $\mathrm{NaHCO}_{3}$ for p.o. immunizations) respectively, or intraperitoneally for the Ribi adjuvant. For evaluating humoral responses, immunized mice were give a booster dose of $50 \mu \mathrm{g}$ endotoxin-low OVA or $25 \mu \mathrm{g}$ NP-CGG intraperitoneally at day 10 after the primary immunization, and serum was collected at day 18 .

Preparation of fusion proteins and conjugates. CT-OVA and CTBOVA conjugates were prepared, with adjustments to the protocol, as previously described in detail. ${ }^{33}$ In short, $2 \mathrm{mg}$ of CT (List Biological Laboratories) or rCTB (provided by Dr J. Holmgren at the Department of Medical Microbiology and Immunology, Gothenburg University, Gothenburg, Sweden) was solubilized in $\mathrm{dH}_{2} \mathrm{O}$, and $8 \mathrm{mg} \mathrm{ml}^{-1} \mathrm{~N}$ succinimidyl-(3-(2-pyridyl)-dithio)propionate (SPDP) (PharmaciaUpjohn, Pfizer, New York, NY) was added to the solution. Next, OVA was solubilized in $0.1 \mathrm{M}$ phosphate $/ 0.1 \mathrm{M} \mathrm{NaCl}$ buffer and coupled to SPDP, as described above. The CT/CTB-SPDP and OVA-SPDP preparations were mixed together and incubated at room temperature for $24 \mathrm{~h}$. The conjugates were then dialyzed against PBS, and concentrated on a centrifuge column. The concentration was determined by GM1 ganglioside enzyme-linked immunosorbent assay against a standard preparation of CT or CTB. ${ }^{68}$ The relative OVA content in the conjugates was assessed by rabbit anti-OVA antibodies (Abs) and anti-rabbit IgHRP Abs using the GM1 ganglioside enzyme-linked immunosorbent assay. ${ }^{68}$ The molar ratio of OVA to CT or CTB was always $4: 1$. The CTA1-DD fusion protein was expressed in transformed $E$. coli DH5 cells, grown in SYPPG medium overnight in $500 \mathrm{ml}$ cultures with $100 \mu \mathrm{g} \mathrm{ml}^{-1}$ carbenicillin at $37^{\circ} \mathrm{C}$. Cells were harvested by centrifugation and inclusion bodies containing the fusion proteins were washed and treated with $8 \mathrm{M}$ urea. CTA1-DD was refolded by slow dilution 35-40 times in Tris- $\mathrm{HCl}$ (pH 7.4) at $4{ }^{\circ} \mathrm{C}$. Purification was performed in two steps: by ion exchange and size exclusion chromatography. The protein was then concentrated, sterile filtered, and stored at $-80^{\circ} \mathrm{C}$ until use.

Immunofluorescence staining. Spleens were snap-frozen in OTCembedding medium (Sakura, Tokyo, Japan) using isopentane cooled by liquid nitrogen. For detecting GFP + cells, spleens were fixed in $4 \%$ paraformaldehyde $+10 \%$ sucrose before freezing. Tissue sections $(7 \mu \mathrm{m})$ were prepared on microslides using a Leica cryostat (Wetzlar, Germany, CM3050s). Sections were air dried, fixed in acetone for $10 \mathrm{~min}$, and rehydrated in PBS. Sections were blocked using horse serum diluted 1:20 for $15 \mathrm{~min}$ and then incubated with the Abs of interest for $1 \mathrm{~h}$ in room temperature. The following primary Abs were used: hamster anti-CD11c (BD Pharmingen, Franklin Lakes, NJ), biotin anti-CD86 (BD Pharmingen), or biotin anti-B220 (BD Pharmingen); secondary reagents were: anti-hamster-Cy3 (Jackson ImmunoResearch, West Grove, PA), streptavidin-AlexaFluor-488 (Invitrogen, Carlsbad, CA), or streptavidin-TXRD (Dako, Glostrup, Denmark). Microscopy was performed at the Centre for Cellular Imaging using the confocal Zeiss LSM 510 META system and LSM software (Carl Zeiss, San Jose, CA). All images within an experiment were equivalently manipulated using Photoshop (Adobe Systems, San Jose, CA) to adjust brightness and contrast.
Enzyme-linked immunosorbent assay. For detecting serum Abs, microtiter plates (Maxisorp, Nunc, Roskilde, Denmark) were coated with $10 \mu \mathrm{g} \mathrm{ml}^{-1} \quad \mathrm{NP}_{7} / \mathrm{BSA}$ (Biosearch Technologies), $200 \mu \mathrm{g} \mathrm{ml}^{-1}$ OVA (Sigma-Aldrich), $100 \mu \mathrm{g} \mathrm{ml}^{-1} \mathrm{KLH}$ (Calbiochem, Darmstadt, Germany), or $0.5 \mathrm{nmol} \mathrm{ml}^{-1}$ GM1 (Sigma, St Louis, MO), followed by $0.5 \mu \mathrm{g} \mathrm{ml}^{-1} \mathrm{CT}$ (List Biological Laboratories) in PBS at $4{ }^{\circ} \mathrm{C}$ overnight. Plates were washed with PBS and blocked with $0.1 \%$ bovine serum albumin (BSA)/PBS for $30 \mathrm{~min}$ at $37^{\circ} \mathrm{C}$. Serum samples were diluted 1:50 in $0.1 \% \mathrm{BSA} / \mathrm{PBS}$ and loaded to the plates. A series of 1:3 dilutions of the samples in corresponding subwells were performed and incubated for $2 \mathrm{~h}$ in room temperature. Plates were washed with PBS-Tween and alkaline phosphatase-conjugated goat anti-mouse $\mathrm{IgG}_{1}$ or $\mathrm{IgG}_{2 \mathrm{c}}$ Abs (Southern Biotechnology Associates, Birmingham, $\mathrm{AL}$ ) were added to the wells, diluted $1: 500$ in $0.1 \% \mathrm{BSA} / \mathrm{PBS}$, and incubated for $2 \mathrm{~h}$ at room temperature. Ag-specific Abs were visualized using phosphatase substrate tablets, nitrophenyl disodium salt hexahydrate (Sigma-Aldrich), dissolved at $1 \mathrm{mg} \mathrm{ml}^{-1}$ in ethanolamine buffer ( $\mathrm{pH}$ 9.8). Absorbance was measured at $405 \mathrm{~nm}$ using a Multiscan MS spectrophotometer, Multiskan, Thermo Scientific (Waltham, MA). The linear part of the curve was used for calculating titers at a cutoff value of 0.4. For detection of cytokines (Figure 21), the IL-17A and IL-22 DuoSet kit (R\&D Systems, Minneapolis, MN) were used according to the manufacturer's instructions.

Preparation of cell suspensions for adoptive transfer. CD45.1 ${ }^{+} \mathrm{T}$ cells specific for OVA were purified by negative selection using MACS (Miltenyi Biotec, Bergisch Gladbach, Germany). Spleens from OT-II mice were forced through a nylon mesh using a syringe plunger and cell suspensions were pooled. Erythrocytes were lysed by incubation with ammonium chloride for $5 \mathrm{~min}$, and cells were washed in $2 \%$ fetal calf serum/PBS. Cells were then incubated with CD4 ${ }^{+}$T-cell biotin antibody cocktail followed by biotin beads according to the manufacturer's instructions (Miltenyi Biotec). Purity of eluted T cells was controlled using flow cytometry (typically $\sim 85-90 \%$ ). For labeling with carboxyfluorescein succinimidyl ester, the Vybrant CFDA SE Cell Tracer Kit (Molecular Probes, Eugene, OR) was used according to the manufacturer's instructions. $1-3 \times 10^{6}$ cells were injected i.v. into CD $45.2^{+}$recipient mice in $200 \mu$ PBS. NP-GFP B cells were purified by negative MACS separation using a B-cell isolation kit (Miltenyi Biotec). NP-specific B cells were further enriched by depletion of Igא ${ }^{+}$ cells (anti-IgK-PE (BD Pharmingen) and anti-PE beads (Miltenyi Biotec)). Mice were injected i.v. with $1 \times 10^{5}$ cells. For DC reconstitution, DCs were expanded in vivo by subcutaneously injecting WT mice with B16 Flt3L-secreting tumor cells. CD11c ${ }^{+}$DCs were enriched by positive selection using CD11c magnetic beads (Miltenyi Biotec), and the purity was $>98$. Mice were reconstituted with $5 \times 10^{6}$ DCs because preliminary experiments had shown that only $\sim 5 \%$ of the transferred DCs could be retrieved from the spleen after $24 \mathrm{~h}$. All MACS samples were separated using an autoMACS Pro Separator (Miltenyi Biotec). To secure that only naive OT-II cells were adoptively transferred in all experiments, we sorted the cells to very high purity on the following criteria: $\mathrm{CD} 4{ }^{+} \mathrm{CD} 19^{-} \mathrm{CD}_{2} 2 \mathrm{~L}^{+} \mathrm{CD} 25^{-}$using a FACSAria III (BD Biosciences).

Flow cytometry and fluorescence-activated cell sorting. Spleens were forced through a nylon mesh using a syringe plunger; when analyzing DC populations, the spleens were first enzymatically digested using Liberase (Roche, Penzberg, Germany). Erythrocytes were lysed using ammonium chloride and the cells were washed 3 times in Hanks' balanced salt solution (Life Technologies, Carlsbad, CA). Cells were resuspended in $0.1 \%$ BSA/PBS with $5 \mathrm{~mm}$ EDTA and incubated with the FcR blocking antibody (2.4G2) for $5 \mathrm{~min}$, followed by staining with directly conjugated Abs. 7-Aminoactinomycin D (Sigma-Aldrich) was included to eliminate nonviable cells. For intracellular staining of cytokines and Ki-67, the Foxp3/transcription factor staining buffer set (eBiosciences, San Diego, CA) was used according to the manufacturer's instructions, and nonviable cells were detected using the LIVE/DEAD Fixable Aqua Stain (Molecular Probes). When detecting phosphorylated STAT proteins, the BD 
Phosflow protocol was used with Perm Buffer III (BD Biosciences) according to the manufacturer's instructions. After labeling, cells were washed twice and analyzed using an LSR-II (BD Pharmingen). Live gates were set on lymphocytes by forward and side scatter. The Abs used for flow cytometry are listed in Supplementary Table S1.

In vitro culture and cytokine assay. At 8 days after immunization, spleens were removed, and single-cell suspensions were prepared. A total of $2 \times 10^{6}$ cells per ml were cultured in 96-well plates (Nunc) in Iscove's medium (GE Healthcare Life Sciences, Logan, UT) supplemented with $10 \%$ heat-inactivated fetal calf serum (Biochrom, Cambridge, UK), $50 \mu \mathrm{M}$ 2-ME (Sigma-Aldrich), $1 \mathrm{~mm}$ L-glutamine (Biochrom), and $50 \mu \mathrm{g} \mathrm{ml}^{-1}$ gentamicin (Sigma-Aldrich) for $96 \mathrm{~h}$ at $37^{\circ} \mathrm{C}$ in $5 \% \mathrm{CO}_{2}$ either with medium alone or with endotoxin-low $2 \mathrm{mg} \mathrm{ml}^{-1}$ OVA (Sigma-Aldrich). Supernatants were analyzed for cytokines after $96 \mathrm{~h}$ by flow cytometry using a mouse Th1/Th2/Th17/ Th22 13plex FlowCytomix Multiplex kit (eBiosciences) according to the manufacturer's instructions. For analysis of intracellular cytokines, cells were cultured as described above with the addition of $50 \mathrm{ng} \mathrm{ml}^{-1}$ phorbol 12-myristate 13-acetate (Sigma-Aldrich), $500 \mathrm{ng} \mathrm{ml}^{-1}$ ionomycin (Calbiochem), and $10 \mu \mathrm{g} \mathrm{ml}^{-1}$ brefeldin (Sigma-Aldrich) for $6 \mathrm{~h}$.

Quantitative real-time PCR. Total RNA was extracted using the RNeasy Mini Kit (Qiagen, Venlo, The Netherlands), and genomic DNA was eliminated using a DNAse treatment step according to the manufacturer's instructions. Complementary DNA was made using the QuantiTect rev. transcription kit (Qiagen). Quantitative real-time PCR reactions were prepared with LightCycler 480 SYBR green I master (Roche) and $0.5 \mu \mathrm{M}$ of forward and reverse primers in a final volume of $20 \mu$. The following primers were used: HPRT forward $5^{\prime}$-TCCTCCTCAGACCGCTTTT- ${ }^{\prime}$ and reverse $5^{\prime}$-CCTGGTTCATCATCGCTAATC- $3^{\prime}$; RORC forward $5^{\prime}$ TGAGGATGAGATTGCCCTCTA- $3^{\prime}$ and reverse $5^{\prime}$-TTGCAGAT GTTCCACTCTCCT-3'; Tbx21 forward 5'-TCAACCAGCACCAGACAGAG- $3^{\prime}$ and reverse $5^{\prime}$-AAACATCCTGTAATGGCTTGTG-3'; $G A$ TA-3 forward $5^{\prime}$-CTTATCAAGCCCAAGCGAAG- $3^{\prime}$ and reverse $5^{\prime}$-CC CATTAGCGTTCCTCCTC-3'; GNAS forward 5'-TTCGGTCTCGTCC CCTTAGTTG-3' and reverse; $5^{\prime}$-AACAAATCGCACACCCCAGTG AGG-3'. In Figure 1e, a RealTime ready custom RT-qPCR 96-well array plate (Roche) was used, and quantitative real-time PCR was performed on a light cycler 480 system (Roche).

Statistical analysis. Comparisons between groups were done using the Mann-Whitney test. The analyses were performed using the Prism software (GraphPad, La Jolla, CA). Error bars represent values of s.d. All reported $P$-values are two sided and values of $<0.05$ were considered to indicate statistical significance $\left({ }^{\star} P<0.05\right.$ and $\left.{ }^{\star *} P<0.01\right)$.

SUPPLEMENTARY MATERIAL is linked to the online version of the paper at http://www.nature.com/mi

\section{ACKNOWLEDGMENTS}

This study was supported by research funds from the Swedish Cancer Foundation, Vetenskapsrådet Medicin, Strategiska Stiftelserna, Knut och Alice Wallenbergs Stiftelse, AFA-försäkringar, EU projects in FP7 UniVacFlu, and UNISEC. We thank Dr Weinstein for generously providing the Gs $\alpha$-floxed mice (NIH, Bethesda, MD, USA). We also thank the Centre for Cellular Imaging and the Laboratory for Experimental Biomedicine facility at the University of Gothenburg for excellent help and expert advice.

\section{DISCLOSURE}

The authors declared no conflict of interest.

c) 2015 Society for Mucosal Immunology

\section{REFERENCES}

1. Lycke, N. Recent progress in mucosal vaccine development: potential and limitations. Na.t Rev. Immunol. 12, 592-605 (2012).
2. Mattsson, J. \& Lycke, N.Y. Bacterial enterotoxins as immunomodulators and vaccine adjuvants. In Bacterial Toxins: Genetics, Cellular Biology and Practical Applications (Proft, T., ed) 93-114 (Caister Academic Press, Norfolk, UK, 2013).

3. Lavelle, E.C. et al. Effects of cholera toxin on innate and adaptive immunity and its application as an immunomodulatory agent. J. Leukoc. Biol. 75, 756-763 (2004).

4. Holmgren, J. \& Czerkinsky, C. Mucosal immunity and vaccines. Nat. Med. 11 (4 Suppl), S45-S53 (2005).

5. Freytag, L.C. \& Clements, J.D. Mucosal adjuvants. Vaccine 23 , 1804-1813 (2005).

6. Rappuoli, R., Pizza, M., Douce, G. \& Dougan, G. Structure and mucosal adjuvanticity of cholera and Escherichia coli heat-labile enterotoxins. Immunol. Today 20, 493-500 (1999).

7. Pizza, M. et al. Mucosal vaccines: non toxic derivatives of LT and CT as mucosal adjuvants. Vaccine 19, 2534-2541 (2001).

8. Freytag, L.C., Clements, J.D., Grdic Eliasson, D. \& Lycke, N.Y. Use of genetically or chemically detoxified mutants of Cholera and Escherichia coli heat-labile enterotoxins as mucosal adjuvants. In New Generation Vaccines (Levine, M.M., ed) 273-283 (Informa Healthcare, New York, 2010).

9. Gustafsson, T., Hua, Y.J., Dahlgren, M.W., Livingston, M., JohanssonLindbom, B. \& Yrlid, U. Direct interaction between cholera toxin and dendritic cells is required for oral adjuvant activity. Eur. J. Immunol. 43, 1779-1788 (2013).

10. Fahlen-Yrlid, L. et al. CD11c(high )dendritic cells are essential for activation of CD4 + T cells and generation of specific antibodies following mucosal immunization. J. Immunol. 183, 5032-5041 (2009).

11. Lavelle, E.C., McNeela, E., Armstrong, M.E., Leavy, O., Higgins, S.C. \& Mills, K.H. Cholera toxin promotes the induction of regulatory T cells specific for bystander antigens by modulating dendritic cell activation. J. Immunol. 171, 2384-2392 (2003).

12. Grdic, D. et al. Splenic marginal zone dendritic cells mediate the cholera toxin adjuvant effect: dependence on the ADP-ribosyltransferase activity of the holotoxin. J. Immunol. 175, 5192-5202 (2005).

13. Anjuere, F. et al. In vivo adjuvant-induced mobilization and maturation of gut dendritic cells after oral administration of cholera toxin. J. Immunol. 173, 5103-5111 (2004).

14. Olvera-Gomez, I. et al. Cholera toxin activates nonconventional adjuvant pathways that induce protective CD8 T-cell responses after epicutaneous vaccination. Proc. Natl. Acad. Sci. USA 109, 2072-2077 (2012).

15. Song, J.H. et al. CCR7-CCL19/CCL21-regulated dendritic cells are responsible for effectiveness of sublingual vaccination. J. Immunol. 182, 6851-6860 (2009).

16. Lee, A.Y. et al. Dendritic cells in colonic patches and iliac lymph nodes are essential in mucosal IgA induction following intrarectal administration via CCR7 interaction. Eur. J. Immunol. 38, 1127-1137 (2008).

17. Blazquez, A.B. \& Berin, M.C. Gastrointestinal dendritic cells promote Th2 skewing via OX4OL. J. Immunol. 180, 4441-4450 (2008).

18. Marinaro, M. et al. Mucosal adjuvant effect of cholera toxin in mice results from induction of Thelper 2 (Th2) cells and IL-4. J. Immunol. 155, 4621-4629 (1995).

19. Xu-Amano, J., Jackson, R.J., Fujihashi, K., Kiyono, H., Staats, H.F. \& McGhee, J.R. Helper Th1 and Th2 cell responses following mucosal or systemic immunization with cholera toxin. Vaccine 12, 903-911 (1994).

20. Hornquist, E. \& Lycke, N. Cholera toxin adjuvant greatly promotes antigen priming of T cells. Eur. J. Immunol. 23, 2136-2143 (1993).

21. Jones, H.P., Hodge, L.M., Fujihashi, K., Kiyono, H., McGhee, J.R. \& Simecka, J.W. The pulmonary environment promotes Th2 cell responses after nasal-pulmonary immunization with antigen alone, but Th1 responses are induced during instances of intense immune stimulation. J. Immunol. 167, 4518-4526 (2001).

22. Meza-Sanchez, D., Perez-Montesinos, G., Sanchez-Garcia, J., Moreno, J. \& Bonifaz, L.C. Intradermal immunization in the ear with cholera toxin and its non-toxic beta subunit promotes efficient Th1 and Th17 differentiation dependent on migrating DCs. Eur. J. Immunol. 41, 2894-2904 (2011).

23. la Sala, A. et al. Cholera toxin inhibits IL-12 production and CD8alpha + dendritic cell differentiation by cAMP-mediated inhibition of IRF8 function. J. Exp. Med. 206, 1227-1235 (2009).

24. Braun, M.C., He, J., Wu, C.Y. \& Kelsall, B.L. Cholera toxin suppresses interleukin (IL)-12 production and IL-12 receptor beta1 and beta2 chain expression. J. Exp. Med. 189, 541-552 (1999). 
25. Li, X. et al. Divergent requirement for Galphas and CAMP in the differentiation and inflammatory profile of distinct mouse Th subsets. J. Clin. Invest. 122, 963-973 (2012).

26. Yao, C., Hirata, T., Soontrapa, K., Ma, X., Takemori, H. \& Narumiya, S. Prostaglandin $\mathrm{E}(2)$ promotes Th1 differentiation via synergistic amplification of IL-12 signalling by cAMP and PI3-kinase. Nat. Commun. 4, 1685 (2013).

27. Hervouet, C. et al. Langerhans cells prime IL-17-producing T cells and dampen genital cytotoxic responses following mucosal immunization. J. Immunol. 184, 4842-4851 (2010).

28. Lee, J.B., Jang, J.E., Song, M.K. \& Chang, J. Intranasal delivery of cholera toxin induces th17-dominated T-cell response to bystander antigens. PLoS One 4, e5190 (2009).

29. Datta, S.K. et al. Mucosal adjuvant activity of cholera toxin requires Th17 cells and protects against inhalation anthrax. Proc. Natl. Acad. Sci. USA 107, 10638-10643 (2010).

30. Hirota, K. et al. Plasticity of Th17 cells in Peyer's patches is responsible for the induction of T cell-dependent IgA responses. Nat. Immunol. 14, 372-379 (2013).

31. Agren, L.C., Ekman, L., Lowenadler, B., Nedrud, J.G. \& Lycke, N.Y. Adjuvanticity of the cholera toxin A1-based gene fusion protein, CTA1-DD, is critically dependent on the ADP-ribosyltransferase and Ig-binding activity. J. Immunol. 162, 2432-2440 (1999).

32. Gustafsson, T., Hua, Y.-J., Dahlgren, M., Livingston, M., JohanssonLindbom, B. \& Yrlid, U. Direct interaction between cholera toxin and dendritic cells is required for oral adjuvant activity. Eur. J. Immunol. 43 , 1779-1788 (2013).

33. Eriksson, K., Fredriksson, M., Nordstrom, I. \& Holmgren, J. Cholera toxin and its B subunit promote dendritic cell vaccination with different influences on Th1 and Th2 development. Infect. Immun. 71, 1740-1747 (2003).

34. Cua, D.J. et al. Interleukin-23 rather than interleukin-12 is the critical cytokine for autoimmune inflammation of the brain. Nature $421,744-748$ (2003).

35. Ghilardi, N., Kljavin, N., Chen, Q., Lucas, S., Gurney, A.L. \& De Sauvage, F.J. Compromised humoral and delayed-type hypersensitivity responses in IL-23-deficient mice. J. Immunol. 172, 2827-2833 (2004).

36. Lighvani, A.A. et al. T-bet is rapidly induced by interferon-gamma in lymphoid and myeloid cells. Proc. Natl. Acad. Sci. USA 98, 15137-15142 (2001).

37. Thierfelder, W.E. et al. Requirement for Stat4 in interleukin-12-mediated responses of natural killer and T cells. Nature 382, 171-174 (1996).

38. Hildner, K. et al. Batf3 deficiency reveals a critical role for CD8alpha + dendritic cells in cytotoxic Tcell immunity. Science 322, 1097-1100 (2008).

39. Agren, L.C., Ekman, L., Lowenadler, B. \& Lycke, N.Y. Genetically engineered nontoxic vaccine adjuvant that combines $B$ cell targeting with immunomodulation by cholera toxin A1 subunit. J. Immunol. 158, 3936-3946 (1997).

40. Caton, M.L., Smith-Raska, M.R. \& Reizis, B. Notch-RBP-J signaling controls the homeostasis of CD8- dendritic cells in the spleen. J. Exp. Med. 204, 1653-1664 (2007).

41. Weinstein, L.S., Xie, T., Zhang, Q.H. \& Chen, M. Studies of the regulation and function of the Gs alpha gene Gnas using gene targeting technology. Pharmacol. Ther. 115, 271-291 (2007).

42. Kahn, R.A. \& Gilman, A.G. ADP-ribosylation of Gs promotes the dissociation of its alpha and beta subunits. J. Biol. Chem. 259, 6235-6240 (1984).

43. Kassis, S., Hagmann, J., Fishman, P.H., Chang, P.P. \& Moss, J. Mechanism of action of cholera toxin on intact cells. Generation of A1 peptide and activation of adenylate cyclase. J. Biol. Chem. 257, 12148-12152 (1982).

44. Gagliardi, M.C., Sallusto, F., Marinaro, M., Langenkamp, A., Lanzavecchia, A. \& De Magistris, M.T. Cholera toxin induces maturation of human dendritic cells and licences them for Th2 priming. Eur. J. Immunol. 30, 2394-2403 (2000).

45. Procopio, D.O. et al. Differential inhibitory mechanism of cyclic AMP on TNF-alpha and IL-12 synthesis by macrophages exposed to microbial stimuli. Br. J. Pharmacol. 127, 1195-1205 (1999).

46. Takeda, K. et al. Defective NK cell activity and Th1 response in IL-18deficient mice. Immunity 8, 383-390 (1998).
47. Yoshida, H. et al. WSX-1 is required for the initiation of Th1 responses and resistance to L. major infection. Immunity 15, 569-578 (2001).

48. Cousens, L.P. et al. Two roads diverged: interferon alpha/beta- and interleukin 12-mediated pathways in promoting $T$ cell interferon gamma responses during viral infection. J. Exp. Med. 189, 1315-1328 (1999).

49. Minter, L.M. et al. Inhibitors of gamma-secretase block in vivo and in vitro T helper type 1 polarization by preventing Notch upregulation of Tbx21. Nat. Immunol. 6, 680-688 (2005).

50. Yoshimoto, T. et al. IL-12 up-regulates IL-18 receptor expression on Tcells, Th1 cells, and B cells: synergism with IL-18 for IFN-gamma production. J. Immunol. 161, 3400-3407 (1998).

51. Takeda, A. et al. Cutting edge: role of IL-27/NSX-1 signaling for induction of T-bet through activation of STAT1 during initial Th1 commitment. J. Immunol. 170, 4886-4890 (2003).

52. Freudenberg, M.A., Merlin, T., Kalis, C., Chvatchko, Y., Stubig, H. \& Galanos, C. Cutting edge: a murine, IL-12-independent pathway of IFNgamma induction by gram-negative bacteria based on STAT4 activation by Type I IFN and IL-18 signaling. J. Immunol. 169, 1665-1668 (2002).

53. Akhiani, A.A., Schon, K. \& Lycke, N. Vaccine-induced immunity against Helicobacter pylori infection is impaired in IL-18-deficient mice. J. Immunol. 173, 3348-3356 (2004).

54. Amsen, D., Blander, J.M., Lee, G. R., Tanigaki, K., Honjo, T. \& Flavell, R.A. Instruction of distinct CD4 Thelper cell fates by different notch ligands on antigen-presenting cells. Cell 117, 515-526 (2004).

55. Skokos, D. \& Nussenzweig, M.C. CD8- DCs induce IL-12-independent Th1 differentiation through Delta 4 Notch-like ligand in response to bacterial LPS. J. Exp. Med. 204, 1525-1531 (2007).

56. Bromander, A., Holmgren, J. \& Lycke, N. Cholera toxin stimulates IL-1 production and enhances antigen presentation by macrophages in vitro. J. Immunol. 146, 2908-2914 (1991).

57. Seo, G.Y., Youn, J. \& Kim, P.H. IL-21 ensures TGF-beta 1-induced IgA isotype expression in mouse Peyer's patches. J. Leukoc. Biol. 85, 744-750 (2009).

58. Ruedl, C. \& Hubele, S. Maturation of Peyer's patch dendritic cells in vitro upon stimulation via cytokines or CD40 triggering. Eur. J. Immunol. 27, 1325-1330 (1997).

59. Kampgen, E. et al. Class II major histocompatibility complex molecules of murine dendritic cells: synthesis, sialylation of invariant chain, and antigen processing capacity are down-regulated upon culture. Proc. Natl. Acad. Sci. USA 88, 3014-3018 (1991).

60. Sjoblom-Hallen, A. et al. Gene expression profiling identifies STAT3 as a novel pathway for immunomodulation by cholera toxin adjuvant. Mucosal. Immunol. 3, 374-386 (2010).

61. Shreedhar, V.K., Kelsall, B.L. \& Neutra, M.R. Cholera toxin induces migration of dendritic cells from the subepithelial dome region to $\mathrm{T}$ - and B-cell areas of Peyer's patches. Infect. Immun. 71, 504-509 (2003).

62. Porgador, A., Staats, H.F., Itoh, Y. \& Kelsall, B.L. Intranasal immunization with cytotoxic T-lymphocyte epitope peptide and mucosal adjuvant cholera toxin: selective augmentation of peptide-presenting dendritic cells in nasal mucosa-associated lymphoid tissue. Infect. Immun. 66, 5876-5881 (1998).

63. Kawamura, Y.I. et al. Cholera toxin activates dendritic cells through dependence on GM1-ganglioside which is mediated by NF-kappaB translocation. Eur. J. Immunol. 33, 3205-3212 (2003).

64. Cong, Y., Weaver, C.T. \& Elson, C.O. The mucosal adjuvanticity of cholera toxin involves enhancement of costimulatory activity by selective upregulation of B7.2 expression. J. Immunol. 159, 5301-5308 (1997).

65. Schwickert, T.A. et al. In vivo imaging of germinal centres reveals a dynamic open structure. Nature 446, 83-87 (2007).

66. Shih, T.A., Roederer, M. \& Nussenzweig, M.C. Role of antigen receptor affinity in T cell-independent antibody responses in vivo. Nat. Immunol. 3 , 399-406 (2002).

67. Nakae, S. et al. Antigen-specific T cell sensitization is impaired in IL-17deficient mice, causing suppression of allergic cellular and humoral responses. Immunity 17, 375-387 (2002).

68. Mueller, C.G. et al. Mannose receptor ligand-positive cells express the metalloprotease decysin in the B cell follicle. J. Immunol. 167, 5052-5060 (2001). 